\title{
Recurrence studies of insect-sized flapping wings in inclined-stroke plane under gusty conditions
}

\author{
M DE MANABENDRA $^{1}{ }^{\mathbb{D}}, \mathrm{J}_{\mathrm{S}} \mathrm{MATHUR}^{2}$ and $\mathrm{S}_{\text {VENGADESAN }}^{3,4, *}$ \\ ${ }^{1}$ Centre for Societal Missions and Special Technologies, CSIR-NAL, Bangalore 560017, India \\ ${ }^{2}$ Computational and Theoretical Fluid Dynamics Division, CSIR-NAL, Bangalore 560017, India \\ ${ }^{3}$ Fluid Mechanics Group, Applied Mechanics Department, Indian Institute of Technology Madras, \\ Chennai 600036, India \\ ${ }^{4}$ Department of Mechanical Engineering, Adjunct Faculty, Virginia Tech, Blacksburg, VA 24601, USA \\ e-mail: vengades@iitm.ac.in
}

MS received 20 February 2018; accepted 10 October 2018; published online 23 February 2019

\begin{abstract}
Global recurrence plots (GRPs) and windowed recurrence quantification analysis (WRQA) are two recurrence paradigms which find wide applications to detect the onset of instability in a dynamic system. The present work reports the attempt to employ these recurrence paradigms to assess the effect of frontal gust on the force patterns of an insect-sized flapping wing in the inclined-stroke plane. Horizontal and vertical forces generated by the flapping wing in the presence of gusts of the form $\frac{\underline{u}_{G}}{u_{w}}=\frac{u_{\infty}}{u_{w}}+\left(\frac{u_{g}}{u_{w}}\right) \sin \left(2 \pi \frac{f_{g}}{f_{w}} t\right)$ were numerically estimated in the $2 \mathrm{D}$ reference frame for $\mathrm{Re}=150$. Nine gusts with combinations of the ratio of gust frequency to wing's flapping frequency, $\mathrm{f}_{\mathrm{g}} / \mathrm{f}_{\mathrm{w}}=0.1,0.5$ and 1 and ratio of gust velocity amplitude to root mean square averaged flapping velocity, $\mathrm{u}_{\mathrm{g}} / \mathrm{u}_{\mathrm{w}}=0.1,0.5$ and 1 were considered. Recurrence studies of the forces were carried out to find out the gusty condition, which would trigger an onset of unstable behaviour. Studies indicated a possible onset of instability in the force patterns for gust with $\mathrm{f}_{\mathrm{g}} / \mathrm{f}_{\mathrm{w}}=0.1$ and $\mathrm{u}_{\mathrm{g}} / \mathrm{u}_{\mathrm{w}}=1$. The onset of unstable behaviour was prominently captured by WRQA of the vertical force coefficient based on determinism (DET) and laminarity (LAM) series.
\end{abstract}

Keywords. Insect-sized flapping wing; inclined-stroke plane; frontal gust; global recurrence plots; windowed recurrence quantification analysis.

\section{Introduction}

Flapping foils find applications in wind energy harvesting as well as anthropogenic flyers like Pico Aerial Vehicles (PAVs). Studies on aerodynamics of flapping wing with different wing kinematics [1-3], wing geometry [4], modes of flight like hovering [5], ascending [6], descending [7], forward flight [8], gliding [9], manoeuvres [10],tandem wing-to-wing positions and kinematics [11] are available in literature. Aero-elastic studies of deforming flapping wings and aero-acoustics have also been reported [12-16]. Studies of ground effects on the flow field in the vicinity of the flapping wings [17, 18] and swarm dynamics [19] have also been documented. Reviews [20-23] published over the past decade have covered these aspects in details.

One important aerodynamic facet of flapping wings is evaluating their performance in the presence of gust. From the experimental studies of small aerial vehicles' flight in the atmospheric boundary layer at a height of $4 \mathrm{~m}$ above

*For correspondence ground [24], it was observed that the roll rates induced by gust increased with a reduction in the span. Numerical evaluation of the effect of the gusty atmosphere on stationary and plunging airfoil [25] indicated that gusty inflow with relatively low frequency could be approximated with a quasi-steady approach for stationary airfoils. Numerical studies of the adverse effects of a sinusoidal gust on flapping wings resulting in the crash of small aerial vehicles were carried out in 2D reference frame [26]. Algebraic moving grid techniques [27] and LES formulations with sub-grid stress [28] have been applied to investigate the flapping airfoil in a gusty environment. These studies reported that the effective angle of attack influenced the structure of leading-edge vortices and consequently the instantaneous vertical and horizontal forces. Effects of a sinusoidal gust on tandem wings [29] have also been reported. These studies indicated that for tandem flapping wings, stationary hind-wing improved gust insensitivity and increased vertical force generation. 2D numerical study of pure and sinusoidal hovering asymmetric flight under zero mean gust using a Lagrangian particle-based algorithm [30] 
reported that mean lift forces exhibited improvements with an increase in fluctuation of the gust amplitude. 2D numerical studies of flow physics in the vicinity of a variable camber plunge airfoil under gusty conditions [31] revealed that variable camber airfoils were capable of mitigating undesirable load on flapping wings under gusty conditions. These studies revealed that for a set of camber shapes, the force pattern was not affected by gust within a certain frequency or gust amplitude band. 3D numerical studies of horizontally flapping wings in the presence of lateral, downward and frontal gusts [32] revealed that the aerodynamic response of insect-scaled flapping wings strongly depended on mutual orientation of the wing stroke plane and the gust velocity vector.

Studies reported thus far on the performance of flapping wing under gusty conditions predominantly focused on estimating thrust or lift patterns alone. Most of the kinematics were confined to pitching and plunging in either horizontal or vertical plane. Gust frequencies, considered for many of these studies were an order of magnitude lower than the flapping frequency. Reynolds number was in the range of $10^{3}$ to $10^{4}$. Findings of these studies were reported based on the time series of forces, non-dimensional force coefficients or their cycle averaged values. The onset of unstable behaviour in flapping wing systems due to gust was explained using numerical visualization techniques like surface pressure contours, 2D or 3D streamlines, vorticity contours, Q-criteria, $\lambda_{2}$ criteria, Lagrangian coherent structures [33] or proper orthogonal decomposition [34]. Some of these approaches are computationally expensive. However, there exist computationally cost-effective yet efficient and simple mathematical paradigms to examine the onset of unstable behaviour in flapping wing systems due to gust. These paradigms are based on the recurrence algorithms applied to the time series of the force patterns of the system.

Traces of recurrence algorithms date back to the Mayan Civilization [35]. Recurrence paradigms have been used by renowned mathematicians like Poincare [36] and Monk [37]. The modern foundation of recurrence plot was laid by Eckmann [38]. Since then, variants of recurrence plots like the global recurrence plots [39], un-thresholded recurrence plots [40], recurrence plots based on corridor threshold [40], perpendicular recurrence plots [41], iso-directional recurrence plots [42] and windowed recurrence plots [43, 44] have been reported. While the recurrence plots with the typology like homogeneity, periodicity, drift and disruption provided an insight into the behaviour of a dynamic system, researchers and mathematicians always felt a need for a quantitative description of the system's dynamics. This need has lead to the postulation of Recurrence Quantification Analysis (RQA). Based on the diagonal structures of the recurrence plots, five recurrence variables viz. recurrence rate, determinism (aka predictability), maximum length of the diagonal structure of recurrence plot (inverse aka divergence), entropy and trend (aka drift) were proposed
[45]. Later, three more variables based on the vertical structures of the recurrence plots were formulated [46]. These variables include laminarity, trapping time and maximum length of the vertical structures. It was claimed that these new measures could find chaos-chaos transitions and made the investigation of intermittency possible even from short and non-stationary data series. These recurrence paradigms have been applied to analyze the behaviour of dynamic systems in different disciplines of research like mathematics, strange attractors, applied physics, physiology, medicine, environmental, earth sciences, psychology and the stock market. Recurrence studies of flapping wing in 2D and constant inflow condition have been reported in [47] to establish the intermittence route to chaos for a flapping system with purely vertically plunge kinematics. Plunging amplitude was considered as the control parameter. Recurrence rate, determinism and maximum length were employed for conclusively establishing the onset of chaos. A recent work [48] based on the fluid-structure interaction of flapping wing in forward flight with constant inflow in an inviscid fluid employed recurrence plots to understand the chaotic behaviour of the dynamic system. The amplitude of the wing actuation force was considered as the control parameter to investigate different complex states of the system.

From these literatures, it was observed that even though recurrence studies have been applied to different research areas, only limited works on employing the recurrence algorithms to understand the behaviour of flapping wings were available. Also, in these limited works, the flapping wings' studies were limited to quiescent flow field or with constant inflow conditions.

In light of the above aspects, the present work focused on applying global recurrence plots (GRP) and windowed recurrence quantification analysis (WRQA) to analyze the force patterns generated by an insect-sized flapping wing in the inclined-stroke plane under the influence of non-zero mean frontal gust and examine the possibility of instability. Control parameters considered in these studies were gust frequency and gust amplitude. All the recurrence variables reported in [45] and [46] were considered.

\section{Methodology}

Numerical formulation, computational domain, grid structure and boundary conditions are briefly reported. Kinematics considered are briefly described. Subsequently, domain, grid, time-step independence studies and validation studies of the solver are reported. Gust model and their details are reported in the next sub-section. A brief introduction of the recurrence studies has been given at the end of this section. 


\subsection{Numerical formulation}

2D unsteady Navier-Stokes equations were solved using the finite volume formulation, considering incompressible and laminar flow for $\mathrm{Re}=150$. This Reynolds number belongs to the typical operational regime of a natural flyer like the Fruit Fly [49] and anthropogenic flyer like the PAVs [50]. Mach number of flapping insect flight is of the order of $10^{-1}$ [51]. Hence, the assumption of incompressible flow regime was justified. Experimental studies of flow past circular cylinders [52, 53] reported that transition from laminar to turbulent flow occurs at $\operatorname{Re}=180 \pm 5$. This supported the assumption of laminar flow regime for the present studies. Mass and momentum equations were solved in a fixed inertial reference frame [54]. The generic integral form of the conservation equation for a scalar quantity $\varnothing$ on an arbitrary control volume, $\mathrm{V}$, with moving boundaries inside it is given in (1):

$$
\begin{gathered}
\frac{\mathrm{d}}{\mathrm{dt}} \int_{V} \rho \emptyset \mathrm{dV}+\int_{\partial \mathrm{V}} \rho \emptyset\left(\overrightarrow{\mathrm{u}}-\overrightarrow{\mathrm{ug}_{\mathrm{g}}}\right) \cdot \mathrm{d} \overrightarrow{\mathrm{A}} \\
=\int_{\partial V} \Gamma \Delta \emptyset \cdot \mathrm{d} \overrightarrow{\mathrm{A}}+\int_{\mathrm{V}} \mathrm{S}_{\phi} \mathrm{d} \mathrm{V}
\end{gathered}
$$

Here $\rho$ is the fluid density, $\overrightarrow{\mathrm{u}}$ is the flow velocity, $\overrightarrow{\mathrm{u}_{\mathrm{g}}}$ is the velocity of the moving mesh, $\Gamma$ is the diffusion coefficient and $S_{\phi}$ is a source term. Second order upwind spatial discretization and second-order implicit temporal discretization were used for the present studies. Pressure Implicit with Splitting of Operator (PISO) scheme [55] was employed for pressure-velocity coupling. The solution was considered to be converged when mass and momentum residues dropped below $10^{-6}$. Spring-based smoothing and local re-meshing based on size functions were used for updating the mesh while marching in time and simulating the flapping motion of the wing. In the spring-based smoothing approach, the edges between any two mesh nodes were modelled as a network of interconnected springs. The initial spacing of the edges before any boundary motion was considered to be in an equilibrium state. A displacement at a given boundary node generated a force. This force resulted in a proportional displacements of all the associated springs connected to that node. The orientation of nodes at the subsequent time-step was arrived at by incorporating these displacement perturbations to the position of the linked nodes in the present time step. In the local re-meshing approach, elemental cells were divided or combined to maintain the size function resolution. For determining the size function, the solver demarcated a bounding box around the zone. Shortest feature length was then located within this bounding box. Subsequently, the bounding box was subdivided based on the shortest feature length and the size function resolution. With this information grid were re-generated. The shortest feature length was then again determined by creating a secondary box around the zone under consideration and then selecting the shortest edge in that box. Subsequently, the size function was evaluated at the vertex of each individual background grid and the re-gridding process was repeated. The smoothening and re-meshing processes were repeated at every time step. Finite volume formulation based solver ANSYS Fluent was used.

\subsection{Domain details and boundary conditions}

Details of the computational domains ABHG and its decomposition are shown in figure 1 . The wing was bounded by a sub-domain, $\Upsilon$, of elliptical shape. Grids in this sub-domain were non-deforming quadrilateral grids. This sub-domain moved along with the wing during the simulation. This non-deforming sub-domain was bounded by a rectangular flow sub-domain, CDFE.

Grids in this sub-domain CDEF were triangular grids which re-gridded and re-meshed as the wing with the nondeforming sub-domain, $\Upsilon$, marched in time and moved as per the prescribed flapping kinematics. Details of the grid are shown in figure 2 .

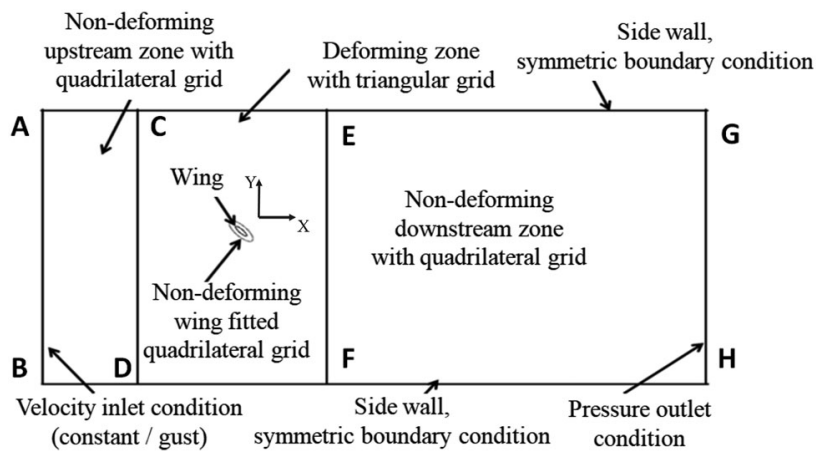

Figure 1. Details of the computational domain.

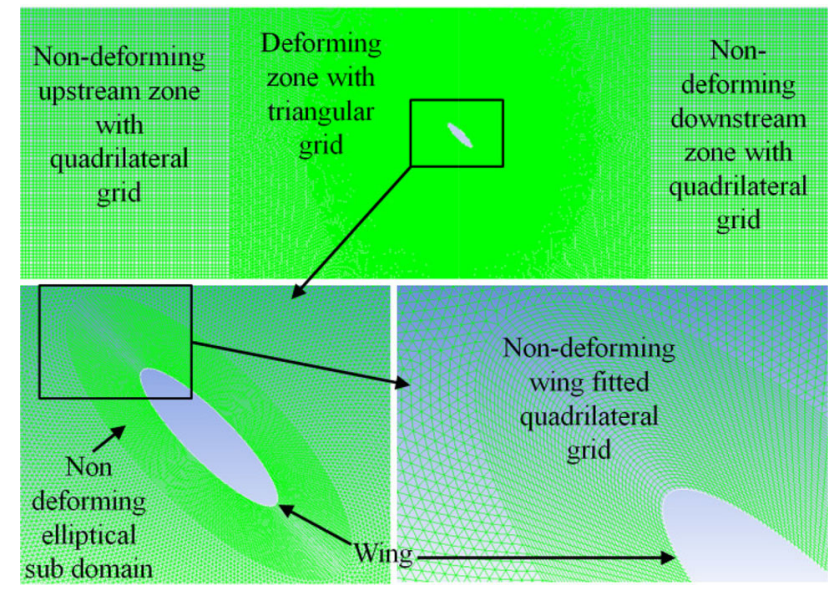

Figure 2. Details of the grid. 


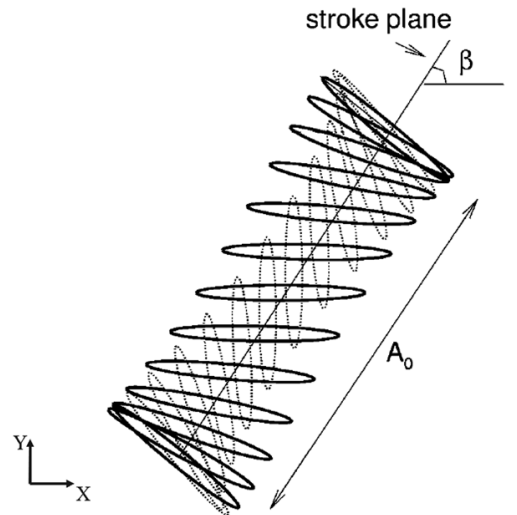

Figure 3. Inclined-stroke plane kinematics [56].

The wing was attributed with impervious wall boundary condition. Edges $\mathrm{CD}$ and EF were considered as interior edges. Edge $\mathrm{AB}$ was attributed with velocity-inflow boundary condition. User-defined function (UDF), a subroutine program written in $\mathrm{C}$, prescribing the gusty velocity inflow conditions was developed and attributed to this edge. Edge $\mathrm{GH}$ was attributed with pressure outlet boundary condition. Edges $\mathrm{AC}, \mathrm{CE}, \mathrm{EG}, \mathrm{BD}, \mathrm{DF}$ and $\mathrm{FH}$ were attributed with symmetric boundary condition.

\subsection{Kinematics}

Simulations were carried out for inclined-stroke plane kinematics (figure 3).

Wing followed the translational position along $\mathrm{X}$ and $\mathrm{Y}$ axis during flapping as given in (2):

$$
[x(t), y(t)]=\frac{A_{0}}{2}\left(1+\cos 2 \pi f^{*} t\right)(\cos \beta, \sin \beta)
$$

Details of the kinematics are given in table 1.

Here, $\mathrm{f}^{*}$ is the non-dimensionalized flapping frequency, $\mathrm{A}_{0} / \mathrm{c}$ is the ratio of stroke length, $\mathrm{A}_{0}$ to the wing chord length, $c$ and $\beta$ is the stroke inclination in degree. The wing rotated about the middle of the chord. For kinematics-1 $[17,56]$, the wing rotated continuously during the entire flapping cycle. For kinematics-2 [57], wing rotation was confined to $20 \%$ of the flapping cycle during pronation and supination. Angle made by the wing with the inclined stroke plane during upstroke and downstroke were $15^{\circ}$ and $50.6^{\circ}$, respectively. Separate UDFs for each kinematics were written.

Kinematics-1 was used for carrying out the convergence studies of the numerical model. The numerical model was then validated against benchmark cases with both the kinematics. Subsequently, kinematics-2 was used to study force patterns of the flapping wing under the influence of frontal gust.

\subsection{Convergence and validation studies}

Convergence studies include domain, grid and time-step independency studies, details of which are reported below.

2.4a Domain independence study: Domain independence study aimed to arrive at the minimum size of the computational domain. Three domain sizes were considered for this study. Details are given in table 2.

Here $\mathrm{c}$ is the dimensional chord length of the wing (length of the major axis of the ellipse). The domain extent along $\mathrm{X}$-axis was chosen based on extent along $\mathrm{X}$-axis considered in the previously reported works [25-29] and kept constant to give sufficient room for the wake to travel downstream. The extent along $\mathrm{Y}$-axis was incremented by $5 c$ on either side. Comparative plots of the predicted instantaneous horizontal and vertical force coefficients are shown in figures 4(a) and (b), respectively.

From the domain independence study, it was observed that there were no significant differences between the predicted instantaneous vertical and horizontal force coefficients using Domain 2 and Domain 3. Hence Domain 2 was chosen for carrying out further simulations.

2.4b Grid independence study: Grid independence study aimed to arrive at the minimum grids resolution for the simulation. Three grids were considered for this study. Details of the grids on the contour of the wing and the entire computational domain are given in table 3 .

Table 2. Details of the domain.

\begin{tabular}{lcc}
\hline Domain & $\mathrm{x}$ & $\mathrm{y}$ \\
\hline Domain 1 & {$[-12 \mathrm{c}, 30 \mathrm{c}]$} & {$[-5 \mathrm{c}, 5 \mathrm{c}]$} \\
Domain 2 & {$[-12 \mathrm{c}, 30 \mathrm{c}]$} & {$[-10 \mathrm{c}, 10 \mathrm{c}]$} \\
Domain 3 & {$[-12 \mathrm{c}, 30 \mathrm{c}]$} & {$[-15 \mathrm{c}, 15 \mathrm{c}]$} \\
\hline
\end{tabular}

Table 1. Details of the kinematics.

\begin{tabular}{lcccccc}
\hline Kinematics & $\mathrm{Re}$ & $\mathrm{f}^{*}$ & $\mathrm{~A}_{0} / \mathrm{c}$ & $\beta(\mathrm{deg})$ & Wing cross-sectional details & Reference \\
\hline Kinematics-1 & 157 & 0.1273 & 2.5 & 60.0 & Ellipse; thickness ratio 0.25 & [17, 56] \\
Kinematics-2 & 150 & 0.0637 & 5.0 & 62.8 & Flat plate; 2\% thickness to chord ratio & [57] \\
\hline
\end{tabular}




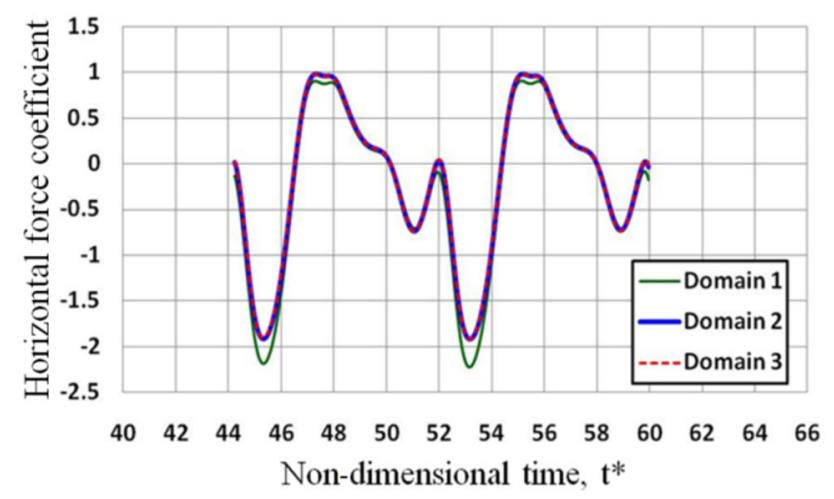

(a) Comparative plots of domain independence studies of horizontal force coefficient.

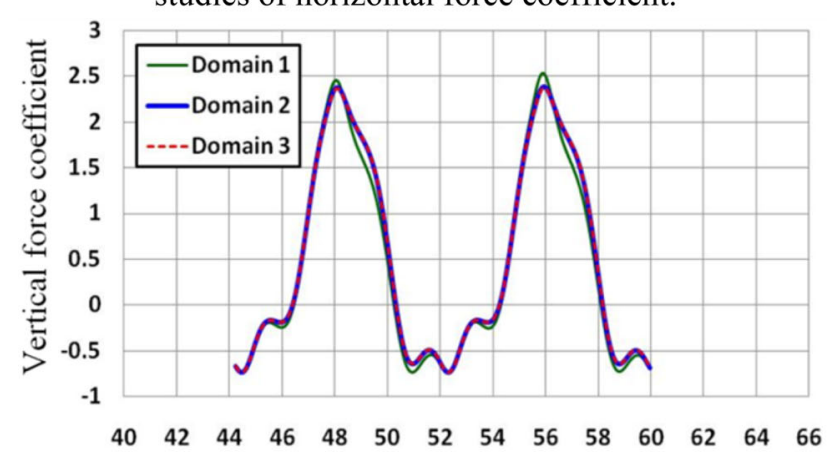

Non-dimensional time, $\mathrm{t}^{*}$

(b) Comparative plots of domain independence studies of vertical force coefficient.

Figure 4. (a) Comparative plots of domain independence studies of horizontal force coefficient. (b) Comparative plots of domain independence studies of vertical force coefficient.

Table 3. Details of the grids.

\begin{tabular}{lcc}
\hline Grid & $\begin{array}{c}\text { No. of grids on the wing's } \\
\text { contour }\end{array}$ & $\begin{array}{c}\text { No. of grids in the } \\
\text { domain }\end{array}$ \\
\hline Grid 1 & 54 & 9,000 \\
Grid 2 & 108 & 35,600 \\
Grid 3 & 216 & $1,41,100$ \\
\hline
\end{tabular}

Here, grids on the wing contour for Grid 2 and Grid 3 were increased by two and three times as compared to Grid 1. No. of grids in the domain for Grid 2 and Grid 3 were increased by approximately four and sixteen times as compared to Grid 1. Comparative plots of the predicted instantaneous horizontal and vertical force coefficients are shown in figures 5(a) and (b), respectively.

From the grid independence study, it was observed that there was no significant difference in the predicted instantaneous vertical and horizontal force coefficients using Grid 2 and Grid 3. Hence Grid 2 was chosen for carrying out further simulations.

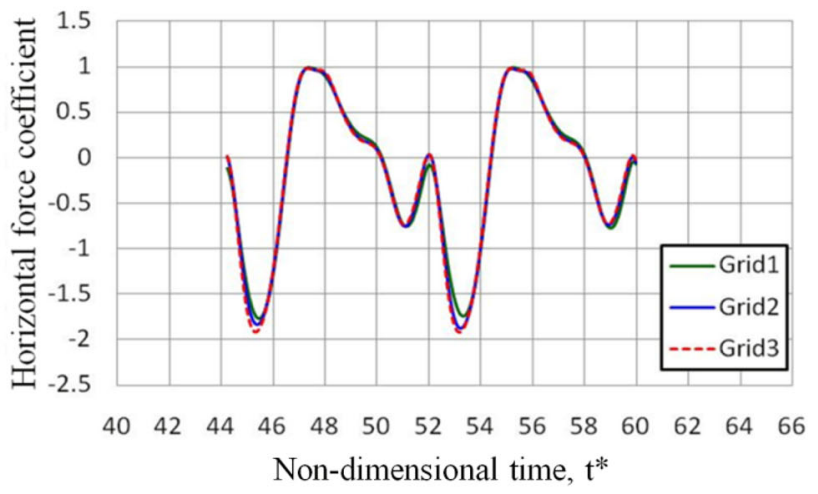

(a) Comparative plots of grid independence studies of horizontal force coefficient.

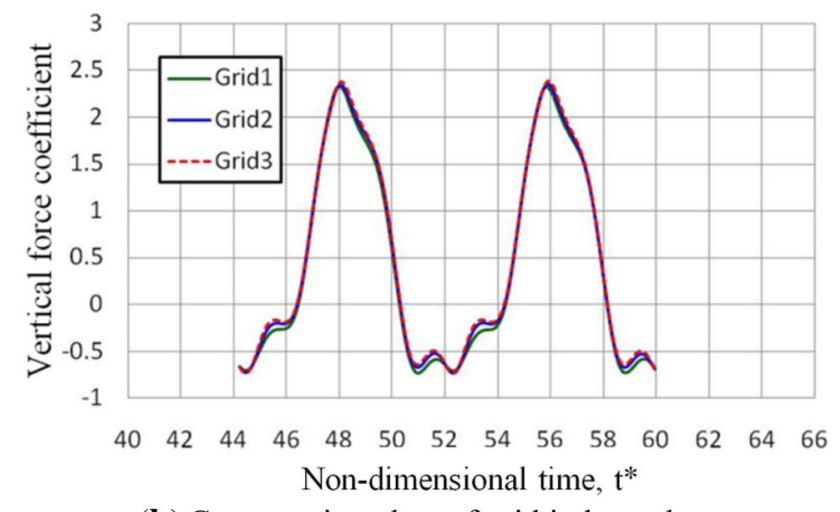

(b) Comparative plots of grid independence studies of vertical force coefficient.

Figure 5. (a) Comparative plots of grid independence studies of horizontal force coefficient. (b) Comparative plots of grid independence studies of vertical force coefficient.

2.4c Time-step independence study: Three time-steps viz. $\mathrm{T} / 200, \mathrm{~T} / 300$ and $\mathrm{T} / 600$ were considered for this study. Here, $\mathrm{T}$ is the flapping period. Comparative plots of the predicted instantaneous horizontal and vertical force coefficients are shown in figures 6(a) and (b), respectively.

From the time-step independence study, it was observed that there was no significant difference in the predicted instantaneous vertical and horizontal coefficients for simulations with time-steps smaller than T/300. Hence timestep chosen for further simulations was $\mathrm{T} / 300$.

2.4d Validation study: Comparison of instantaneous nondimensional horizontal and vertical force coefficients, as predicted by the present methodology, with benchmark cases documented by Wang [56], Gao et al [17] and Sudhakar and Vengadesan [57] at $\mathrm{Re}=157$ for kinematics-1 are shown in figures 7(a) and (b), respectively.

Vorticity plots at different temporal instances during flapping following kinematics-1 were compared against the plots documented in $\mathrm{Xu}$ and Wang [58]. They are shown in figures 8(a), (b), (c) and (d). 


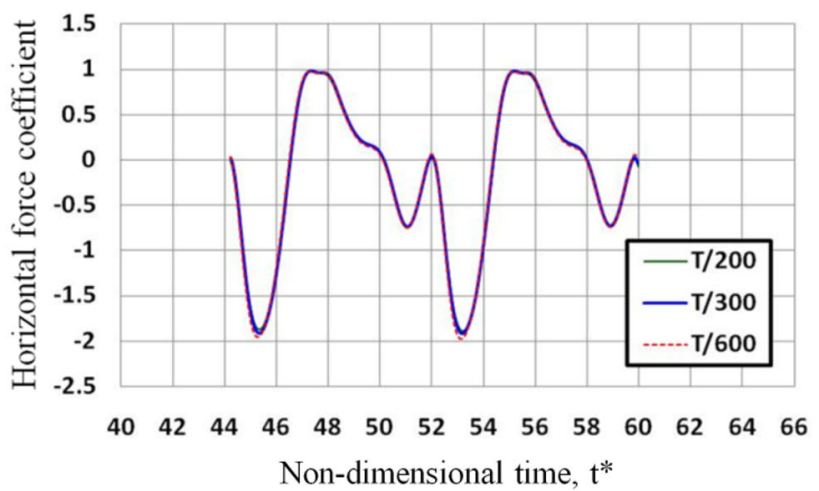

(a) Comparative plots of time-step independence studies of horizontal force coefficient.

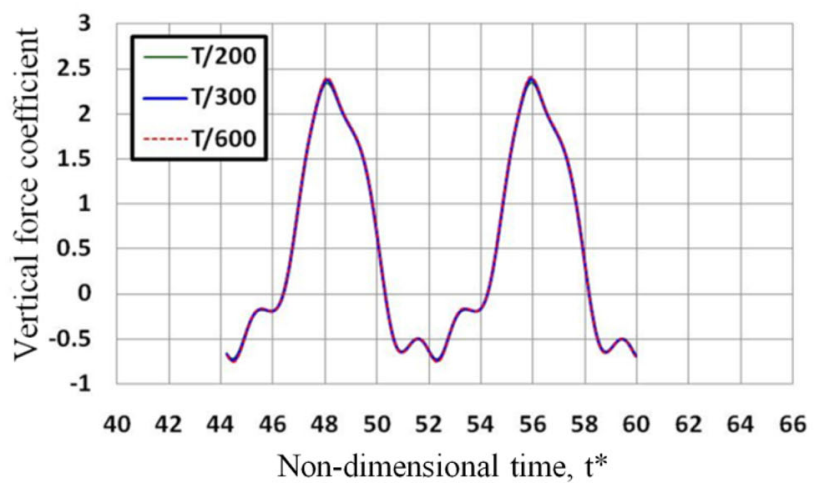

(b) Comparative plots of time-step independence studies of vertical force coefficient.

Figure 6. (a) Comparative plots of time-step independence studies of horizontal force coefficient. (b) Comparative plots of time-step independence studies of vertical force coefficient.

Comparison of instantaneous non-dimensional vertical force coefficient, as predicted by the present methodology, with a benchmark case reported by Sudhakar and Vengadesan [57] at $\mathrm{Re}=150$ for kinematics-2 is shown in figure 9.

These comparisons revealed that the present numerical methodology could handle the unsteady flow physics of flapping wing with reasonable accuracy. For rest of the simulation studies, kinematics-2 [57] was used.

\subsection{Gust model and details}

Harland and Jacob [59] reported different expressions to represent gust. Most commonly adopted temporally varying gust models amongst them were sharp-edged gust and oscillatory gust models. For the present study, the oscillatory gust model was chosen. The generic form is as given in (3):

$$
\frac{u_{G}}{u_{w}}=\frac{u_{\infty}}{u_{w}}+\left(\frac{u_{g}}{u_{w}}\right) \sin \left(2 \pi \frac{f_{g}}{f_{w}} t\right)
$$

Here, $u_{G}$ is the gust velocity in $\mathrm{m} / \mathrm{s}, \mathrm{u}_{\infty}$ is mean free stream velocity in $\mathrm{m} / \mathrm{s}$, $u_{\mathrm{g}}$ is gust amplitude in $\mathrm{m} / \mathrm{s}, \mathrm{f}_{\mathrm{g}}$ is gust frequency in $\mathrm{Hz}, \mathrm{f}_{\mathrm{w}}$ is the wing flapping frequency in $\mathrm{Hz}$ and $t$ is time in second. The velocities were non-dimensionalized using $\mathrm{u}_{\mathrm{w}}$, the root mean square average flapping velocity of the wing in $\mathrm{m} / \mathrm{s}$. For the present study, combination of $\mathrm{f}_{\mathrm{g}} / \mathrm{f}_{\mathrm{w}}=0.1,0.5 \& 1.0$ and $\mathrm{u}_{\mathrm{g}} / \mathrm{u}_{\mathrm{w}}=0.1,0.5$ and 1.0 were considered. This resulted in nine gust models. Details are given in table 4 .

\subsection{Recurrence studies}

Recurrence studies reported in the present work are Global Recurrence Plots (GRP) and Windowed Recurrence Quantification Analysis (WRQA). GRP is an X-Y plot of the times at which a phase space trajectory visits roughly the same area in the phase space diagram at a given moment in time. They describe the distances of every point $x(i)$ to all the other points $x(j)$ in the phase space diagram. The plot is represented by the mathematical expression given in (4):

$$
\operatorname{Dist}(\mathrm{i}, \mathrm{j})=\vartheta(\|\mathrm{x}(\mathrm{i})-\mathrm{x}(\mathrm{j})\|)
$$

Here, $\mathrm{i}$ and $\mathrm{j}=1,2,3, \ldots \ldots \mathrm{N},\|\bullet\|$ is the Euclidean norm operator and $\vartheta(\bullet)$ is the colour code operator that maps the distance to a colour scale. The colour scale in the present work was varied from black to white colour. Black colour in the plot indicated that the points were located close to each other and white colour indicated that the points were located farther apart in the phase space plot.

Textures of the GRPs primarily give a qualitative insight into the behaviour of a dynamic system. Textures indicate whether the behaviour of a dynamic system is homogenous, oscillating, drifting or chaotic in nature. However, they do not distinctly confirm the inferences in a quantitative manner. This subjectivity was addressed by carrying out WRQA of the predicted force patterns. WRQA helped to quantitatively assess any event and precisely judge the possibility of an onset of a system's unstable behaviour. In the present study, all the variables reported in [45] and [46] were employed. They are recurrence rate (RR), determinism (DET), laminarity (LAM), trapping time (TT), ratio (RATIO), entropy (ENTR), maximum line ( $\left.\mathrm{L}_{\max }\right)$ and trend (TREND). In the present study, time period of one flapping cycle was considered as one window period width. This choice was based on the fact that gust caused variation in the inflow conditions between two consecutive flapping cycles. It was envisaged to assess that whether due to the difference in the inflow conditions, the recurrence variables exhibited uneven fluctuations for a given pair of frequency and velocity ratios. A noticeable uneven fluctuation in the recurrence variable series would indicate an onset of instability. Standard deviations of these recurrence variable series were also calculated to ascertain uncertainty or the uneven fluctuation of the 


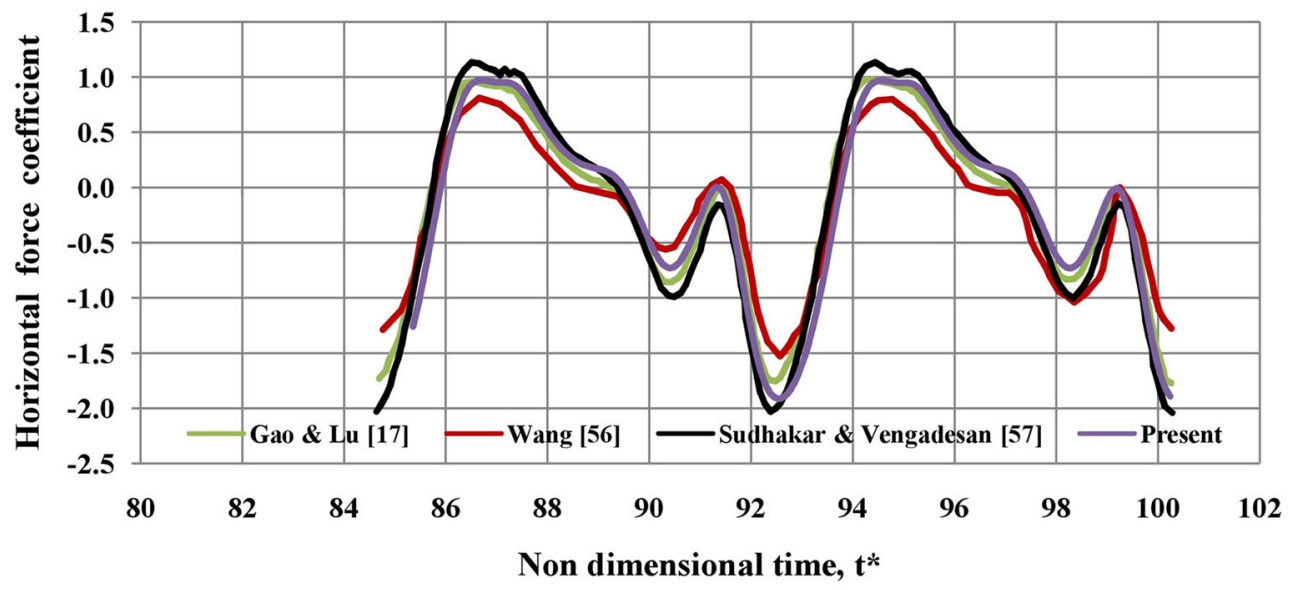

(a) Comparative plots of validation studies of horizontal force coefficient for kinematics-1.

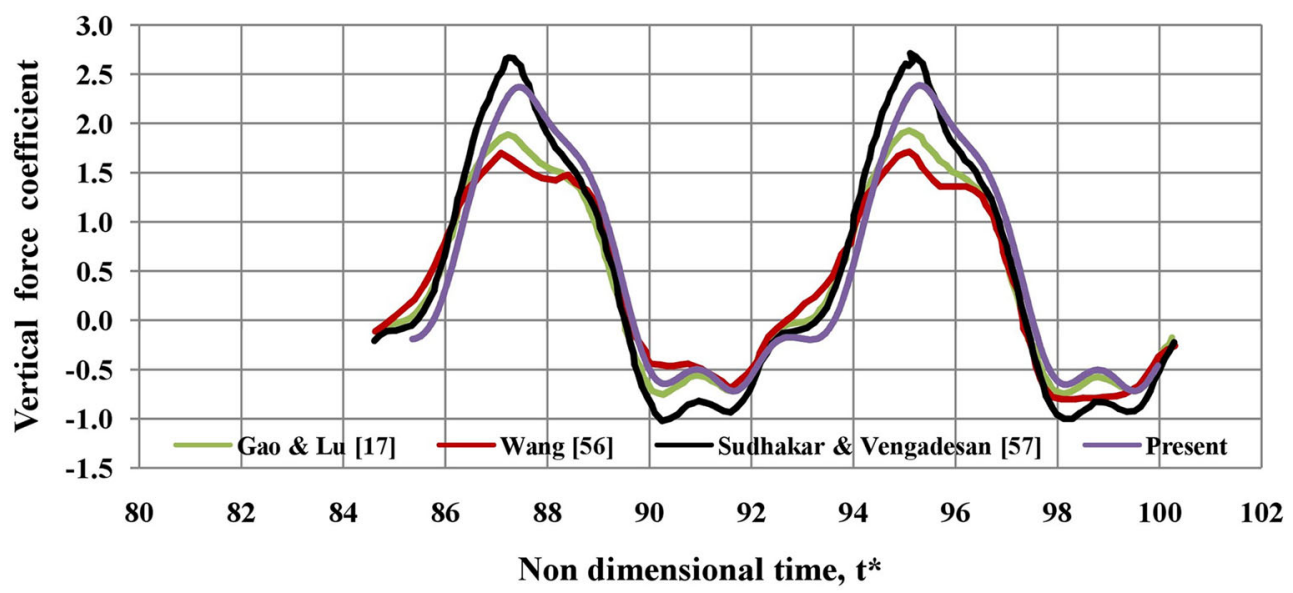

(b) Comparative plots of validation studies of vertical force coefficient for kinematics-1.

Figure 7. (a) Comparative plots of validation studies of horizontal force coefficient for kinematics-1. (b) Comparative plots of validation studies of vertical force coefficient for kinematics- 1 .

series. The lowest $\mathrm{f}_{\mathrm{g}} / \mathrm{f}_{\mathrm{w}}$ ratio considered in the present study was 0.1 i.e., one gust cycle covered ten flapping cycles. Hence force pattern variations between $20^{\text {th }}$ and $30^{\text {th }}$ flapping cycles were considered while computing the recurrence variable series. This duration was chosen since variation in force patterns between $10^{\text {th }}$ and $20^{\text {th }}$ flapping cycle and $20^{\text {th }}$ to $30^{\text {th }}$ flapping cycles were similar. The threshold for computing the recurrence variables was chosen in such a way that the Recurrence Rate was approximately $1 \%$ [60]. All variables were calculated for a dimension of 1 . Euclidean norm was used while defining the neighbourhood radius.

\section{Results and discussions}

\subsection{Force coefficients}

Aerodynamic force vectors were resolved along the horizontal (X-axis) and vertical (Y-axis) directions. Typical force vector resolutions are shown in figures 10(a) and (b). Forces were non-dimensionalized with the dynamic force based on mean free-stream velocity. Temporal variation of the horizontal and vertical force coefficients (non-dimensionalized forces) are shown in figures 11(a) and (b).

\subsection{Phase space diagrams}

Phase space diagrams based on vertical to horizontal force coefficients are shown in figures 12(a)-(i). These plots represented the correlation between the force coefficients under nine different frontal gust conditions. For all the plots, the abscissa and ordinate scales were maintained similar so as to prominently bring out the relative differences among the nine phase space diagrams.

It was observed that the phenomenon remained bounded and did not become chaotic. However, for gust with $\mathrm{f}_{\mathrm{g}} /$ $\mathrm{f}_{\mathrm{w}}=0.1$ and $\mathrm{u}_{\mathrm{g}} / \mathrm{u}_{\mathrm{w}}=1 \& 0.5$ i.e., gust 7 and 8 , the 


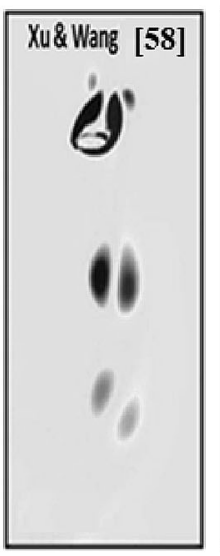

(a) $t=0.25 t_{w}$

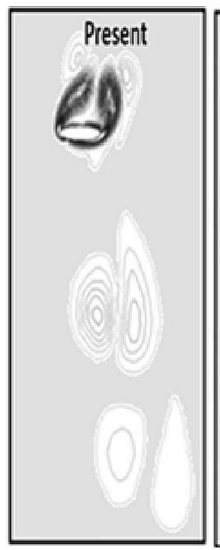

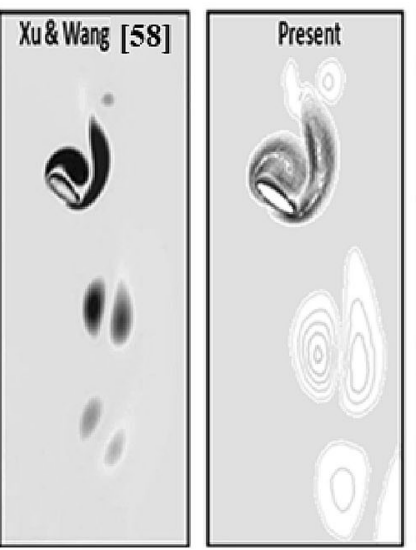

(b) $t=0.44 t_{w}$

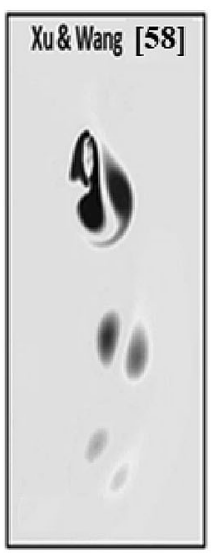

(c) $t=0.74 t_{w}$
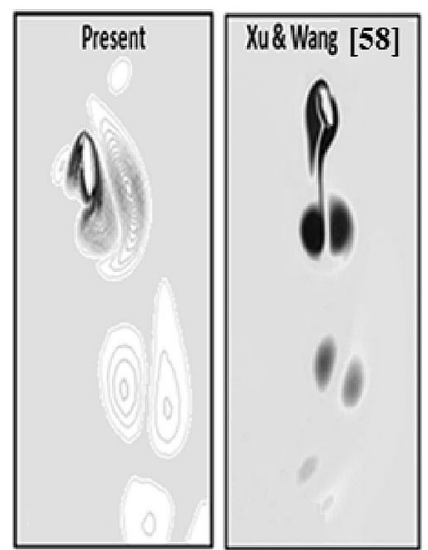

(d) $t=0.99 t_{w}$

Figure 8. Comparision of vorticity contours during different time-steps of flapping cycle for kinematics-1.

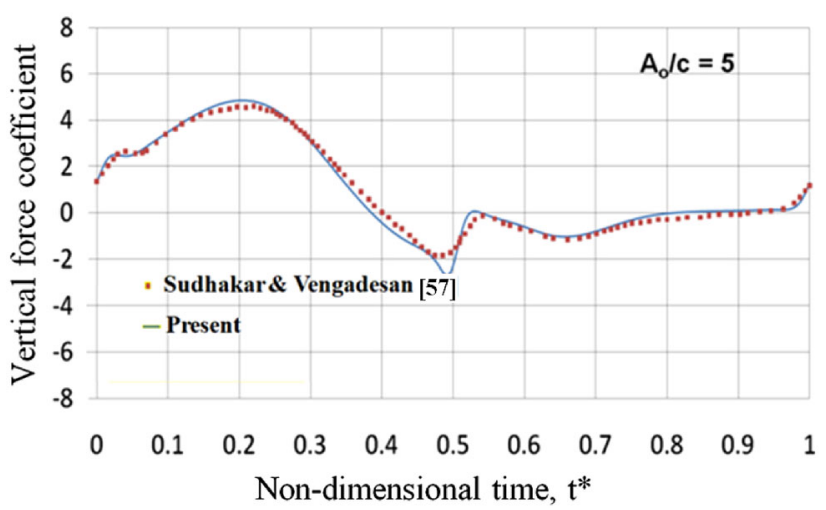

Figure 9. Comparative plots of validation studies of vertical force coefficient for kinematics-2.

correlation between the forces was distorted as compared to the others. This indicated that a gust with a temporal oscillation frequency of an order lesser than the flapping frequency and gust amplitude of same or half order as the root mean square average flapping velocity created an unstable force pattern and thus an unstable flight condition.

Table 4. Details of the gust models.

\begin{tabular}{lcc}
\hline Gust models & $\mathrm{f}_{\mathrm{g}} / \mathrm{f}_{\mathrm{w}}$ & $\mathrm{u}_{\mathrm{g}} / \mathrm{u}_{\mathrm{w}}$ \\
\hline Gust 1 & 1.0 & 1.0 \\
Gust 2 & 1.0 & 0.5 \\
Gust 3 & 1.0 & 0.1 \\
Gust 4 & 0.5 & 1.0 \\
Gust 5 & 0.5 & 0.5 \\
Gust 6 & 0.5 & 0.1 \\
Gust 7 & 0.1 & 1.0 \\
Gust 8 & 0.1 & 0.5 \\
Gust 9 & 0.1 & 0.1 \\
\hline
\end{tabular}

\subsection{Global recurrence plots (GRPs)}

Figure 13(a)-(i) show the GRPs for all the simulations with nine different frontal gust conditions. Textures of the plots were indicators of the relationships between the horizontal and vertical force coefficients. The regular checkerboard pattern of the GRPs indicated that the variations of the force patterns were uniform and periodic in nature. However, recurrence patterns for the gust 7 and 8 with $f_{g} / f_{w-}$ $=0.1$ and $\mathrm{u}_{\mathrm{g}} / \mathrm{u}_{\mathrm{w}}=1$ and 0.5 were observed to be slightly uneven and different from the other recurrence patterns. This was an indication that the force patterns of flapping wings under the influence of gust 7 and 8 were different from the other force patterns.

\subsection{Windowed recurrence quantitative analysis}

The mathematical basis for calculating the recurrence variables are reported in this section. Comparative plots of the windowed series of all eight recurrence variables are shown. Standard deviations of these windowed series were computed and are tabulated here. Standard deviation is higher for a more unevenly fluctuating recurrence variable series. Uneven fluctuation of the recurrence variable series implied unstable force patterns caused due to gusty inflow condition.

3.4a Recurrence rate ( $R R)$ : Recurrence rate is the measure of the density of recurrence points. It is computed using (5) as below:

$$
R R=\frac{1}{N^{2}} \sum_{i, j=1}^{N} R_{i, j}^{m, \varepsilon} \times 100
$$

Here $\mathrm{N}$ is the length of data series and $R_{i, j}^{m, \varepsilon}$ is the recurrence matrix of an m-dimensional phase space trajectory and a neighborhoods radius $\varepsilon$. In the present case, $\mathrm{m}$ was chosen as 1 and $\varepsilon$ was chosen in such a manner that most of the RRs in the WRQA were approximately $1 \%$ [60]. RR 


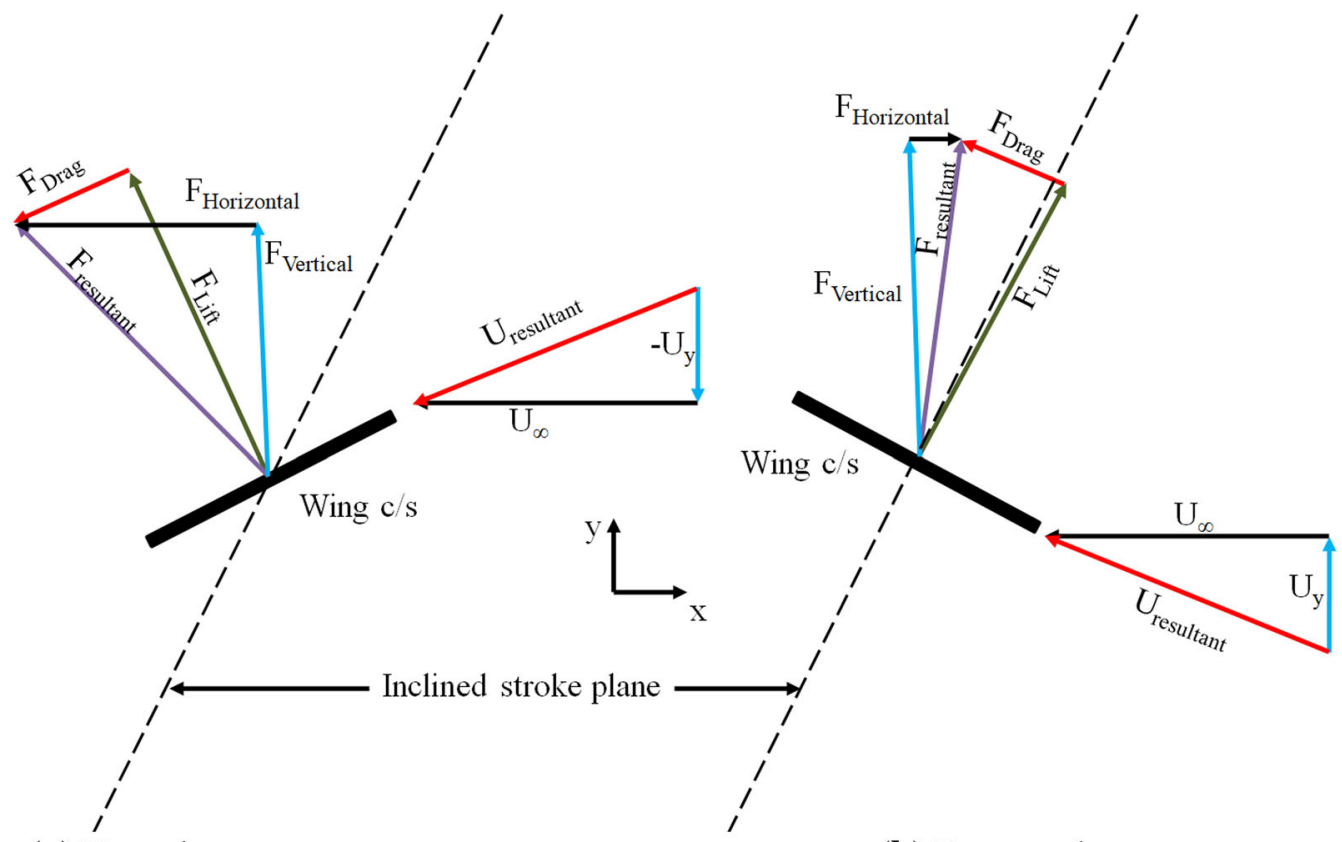

(a) Upstroke

(b) Downstroke

Figure 10. Force vector resolutions.

series for force coefficients are shown in figure 14(a) and (b).

It was observed from the comparative plots of the RR series that for gusts with $\mathrm{f}_{\mathrm{g}} / \mathrm{f}_{\mathrm{w}}$ of 0.1 and $\mathrm{u}_{\mathrm{g}} / \mathrm{u}_{\mathrm{w}}=0.1,0.5$ and 1 i.e., gust 7, 8 and 9, the RR series exhibited more uneven fluctuation as compared to other RR series with higher $\mathrm{f}_{\mathrm{g}} / \mathrm{f}_{\mathrm{w}}$ values.

3.4b Determinism (DET): Determinism (aka predictability) is the ratio of recurrence points that form a diagonal line of length $l_{\min }$ to all the recurrence points. For systems with stochastic nature, DET has smaller value and for systems with periodic behaviour, DET has larger values. It is computed using (6) as below:

$$
D E T=\frac{\sum_{l=l_{\min }}^{N} l P^{\varepsilon}(l)}{\sum_{i, j}^{N} R_{i, j}^{m, \varepsilon}} \times 100
$$

Here $P^{\varepsilon}(l)$ is the frequency distribution of the lengths 1 of the diagonal structures in the recurrence plot with a neighborhoods radius $\varepsilon$ and $l_{\min }$ is the minimum threshold diagonal line. For the present studies, $1_{\min }=2$ was considered. DET series for the horizontal and vertical force coefficients are shown in figures 15(a) and (b).

Comparative plots showed that DET series of force patterns with gust having $\mathrm{f}_{\mathrm{g}} / \mathrm{f}_{\mathrm{w}}=0.1$ and $\mathrm{u}_{\mathrm{g}} / \mathrm{u}_{\mathrm{w}}=1$ i.e., gust 7 fluctuated more unevenly as compared to other DET series.

3.4c Laminarity ( $L A M)$ : Laminarity is the ratio of recurrence points that form a vertical line of length $v_{\min }$ to all the recurrence points. It is the measure of the number of vertical structures in the whole recurrence plot and represents the occurrence of a laminar state in the system without describing the length of these laminar phases. LAM generally decreases if the occurrence of single recurrence points is more than the vertical structures. Mathematical expression to compute LAM is given in (7):

$$
L A M=\frac{\sum_{v=v_{\min }}^{N} v P^{\varepsilon}(v)}{\sum_{i, j}^{N} R_{i, j}^{m, \varepsilon}} \times 100
$$

Here $P^{\varepsilon}(v)$ is the frequency distribution of the lengths $v$ of the vertical structures in the recurrence plot with a neighborhoods radius $\varepsilon$ and $\mathrm{v}_{\min }$ is the minimum threshold vertical line. For the present studies, $v_{\min }=2$ was considered. LAM series for the horizontal and vertical force coefficients are shown in figures 16(a) and (b).

As observed for DET series, LAM series of the force patterns with gust having $\mathrm{f}_{\mathrm{g}} / \mathrm{f}_{\mathrm{w}}=0.1$ and $\mathrm{u}_{\mathrm{g}} / \mathrm{u}_{\mathrm{w}}=1$ i.e., gust 7 exhibited more uneven fluctuations as compared to the other LAM series.

3.4d Trapping time (TT): Trapping time is computed from the vertical structures of the recurrence plots. It represents information about the amount and length of the vertical structures in the recurrence plots. It measures the meantime that the system will be trapped in a specific state. TT is computed as given in (8): 


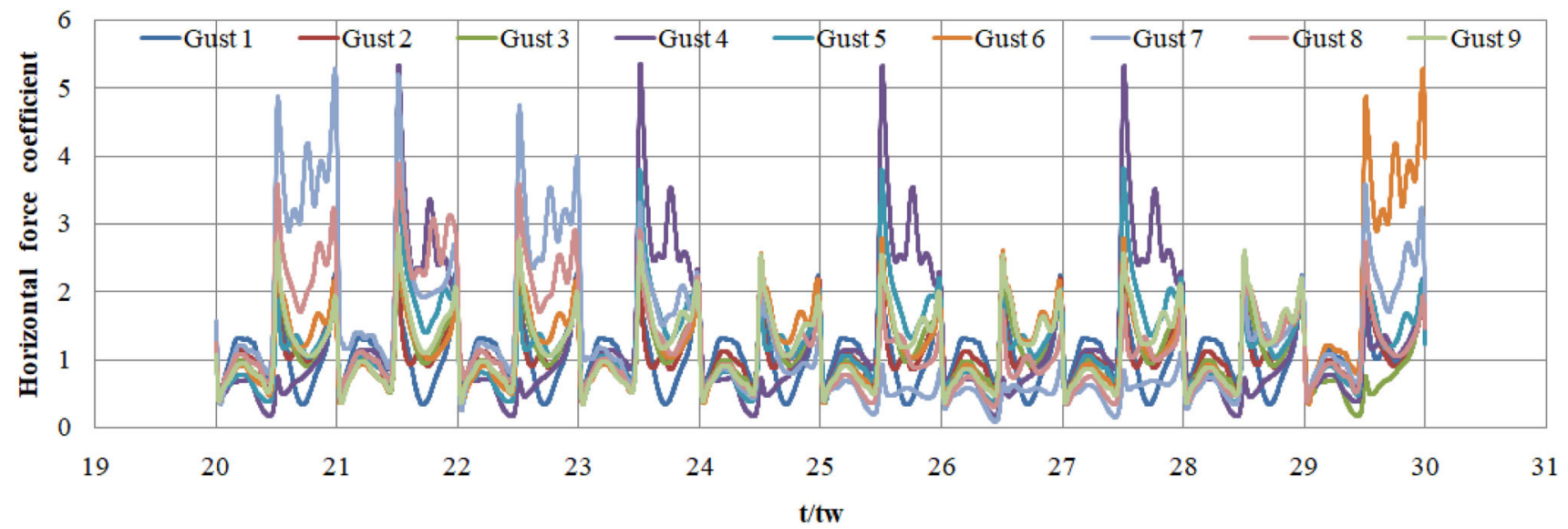

(a) Temporal variation of horizontal force coefficient for different gusts.

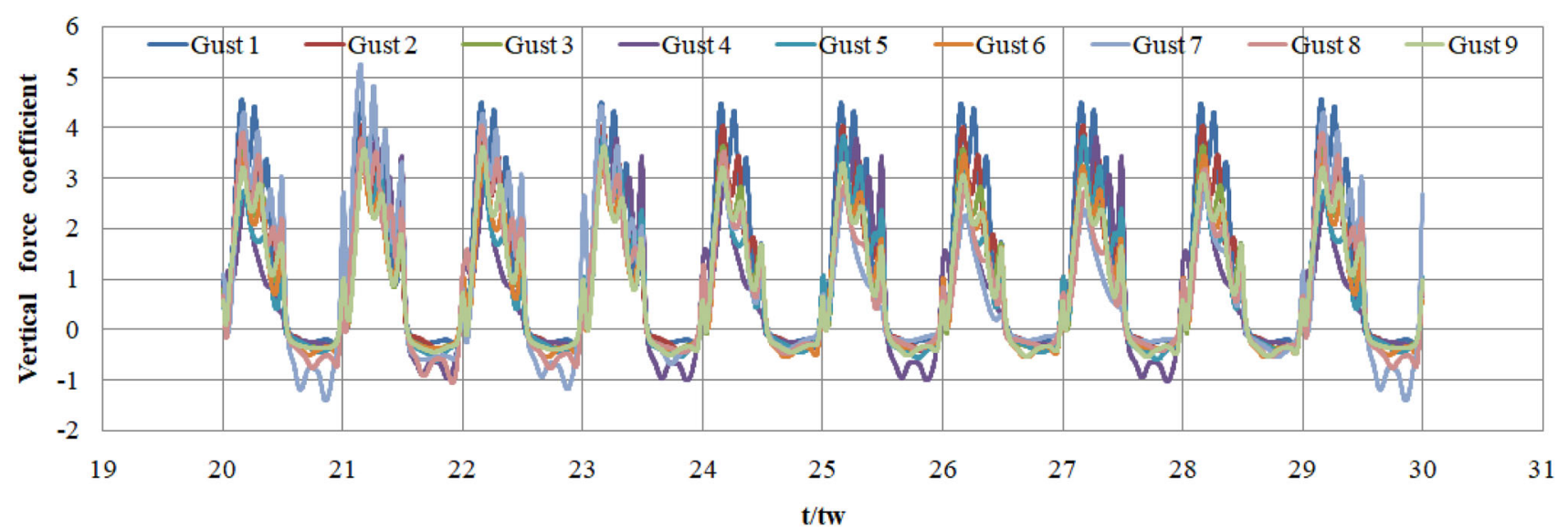

(b) Temporal variation of vertical force coefficient for different gusts.

Figure 11. (a) Temporal variation of horizontal force coefficient for different gusts. (b)Temporal variation of vertical force coefficient for different gusts.

$$
T T=\frac{\sum_{v=v_{\min }}^{N} v P^{\varepsilon}(v)}{\sum_{v=v_{\min }}^{N} P^{\varepsilon}(v)}
$$

TT series for the horizontal and vertical force coefficients are shown in figures $17(\mathrm{a})$ and (b).

It was observed from the comparative plots of the TT series that for gusts with $\mathrm{f}_{\mathrm{g}} / \mathrm{f}_{\mathrm{w}}$ of 0.1 and $\mathrm{u}_{\mathrm{g}} / \mathrm{u}_{\mathrm{w}}=0.1,0.5$ and 1 i.e., gust 7, 8 and 9, the TT series exhibited more uneven fluctuations as compared to the other TT series with higher $\mathrm{f}_{\mathrm{g}} / \mathrm{f}_{\mathrm{w}}$ values. This observation was similar to that inferred from the RR series.

3.4e Ratio (RATIO): Ratio is defined as the ratio between DET and RR. It is used to discover transitions in the behaviour of a dynamic system subjected to the fact that during certain types of transitions RR decrease, whereas DET does not change at the same time. RATIO is computed as given in (9):

$$
R A T I O=N^{2} \frac{\sum_{l=l_{\min }}^{N} l P^{\varepsilon}(l)}{\left(\sum_{i, j}^{N} R_{i, j}^{m, \varepsilon}\right)^{2}}
$$

RATIO series for the horizontal and vertical force coefficients are shown in figure 18(a) and (b).

It was observed from the comparative plots of the RATIO series that for gusts with $\mathrm{f}_{\mathrm{g}} / \mathrm{f}_{\mathrm{w}}$ of 0.1 and $\mathrm{u}_{\mathrm{g}} / \mathrm{u}_{\mathrm{w}}$ $=0.1,0.5$ and 1 i.e., gust 7,8 and 9 , the RATIO series exhibited more uneven fluctuations as compared to the other RATIO series with higher $\mathrm{f}_{\mathrm{g}} / \mathrm{f}_{\mathrm{w}}$ values. This observation was similar to that inferred from RR and TT series.

3.4f Entropy (ENTR): Entropy refers to the Shannon entropy of the frequency distribution of diagonal line length. It is the measure of the complexity of the deterministic structures in a dynamic system. ENTR is calculated as given in (10):

$$
E N T R=-\sum_{l=l_{\min }}^{N} p(l) \ln p(l) ; \quad p(l)=\frac{P^{\varepsilon}(l)}{\sum_{l=l_{\min }}^{N} P^{\varepsilon}(l)}
$$

Here, $l_{\min }=2$ was considered. ENTR series for the horizontal and vertical force coefficients are shown in figures 19(a) and (b). 


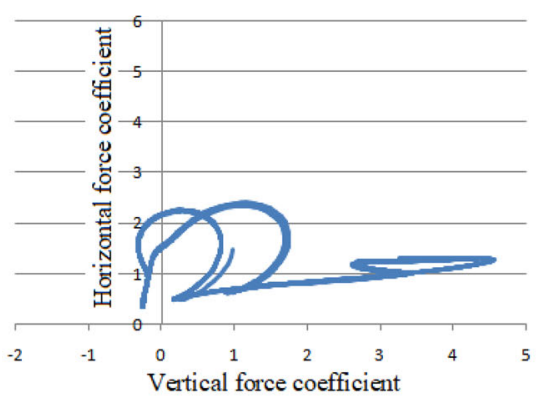

(a) Gust 1

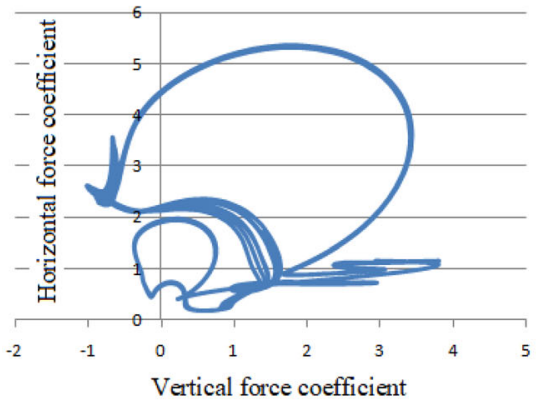

(d) Gust 4

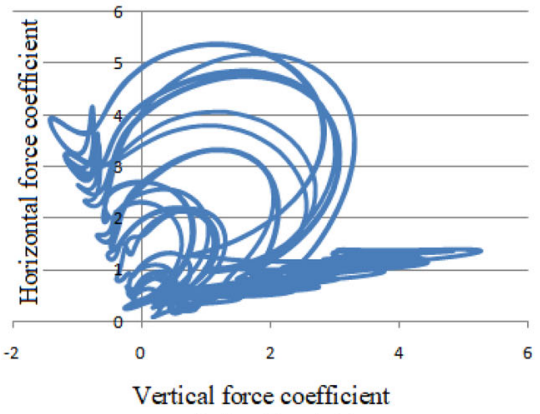

(g) Gust 7

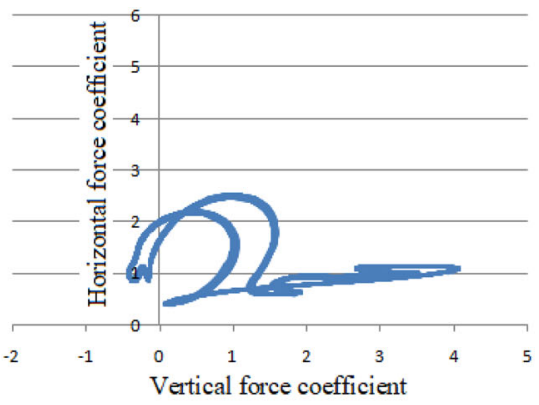

(b) Gust 2

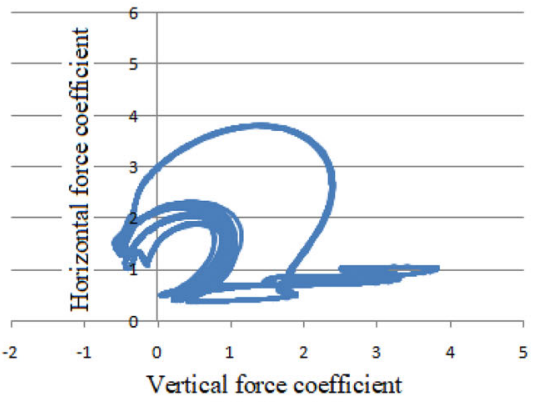

(e) Gust 5

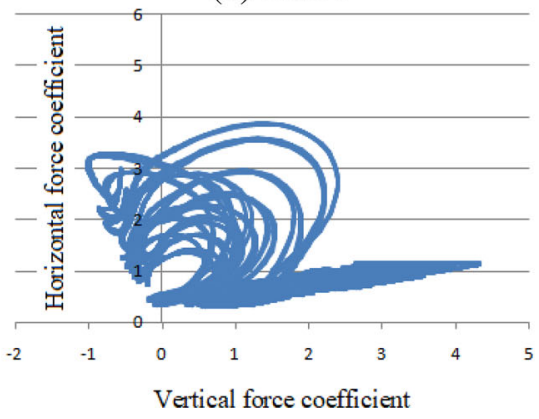

(h) Gust 8

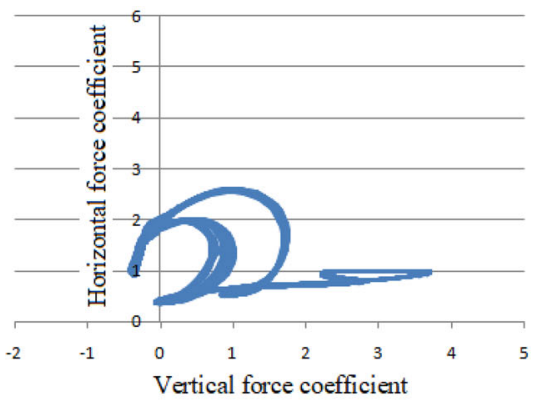

(c) Gust 3

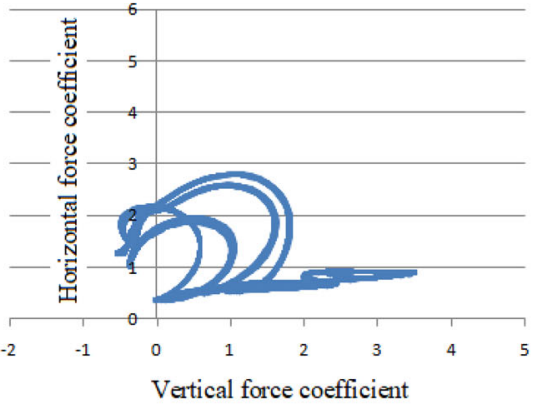

(f) Gust 6

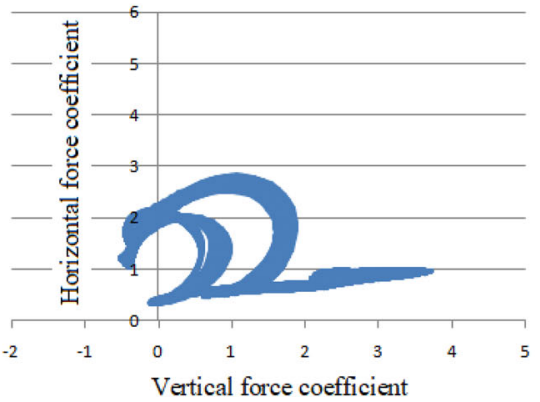

(i) Gust 9

Figure 12. Phase space diagrams of horizontal to vertical force coefficient [top row: $f_{g} / f_{w}=1$; middle row: $f_{g} / f_{w}=0.5$; bottom row: $f_{g} /$ $\mathrm{f}_{\mathrm{w}}=0.1$; left column: $\mathrm{u}_{\mathrm{g}} / \mathrm{u}_{\mathrm{w}}=1$; middle column: $\mathrm{u}_{\mathrm{g}} / \mathrm{u}_{\mathrm{w}}=0.5$; right column: $\left.\mathrm{u}_{\mathrm{g}} / \mathrm{u}_{\mathrm{w}}=0.1\right]$.

It was observed from the comparative plots of the ENTR series that for gusts with $\mathrm{f}_{\mathrm{g}} / \mathrm{f}_{\mathrm{w}}$ of 0.1 and $\mathrm{u}_{\mathrm{g}} / \mathrm{u}_{\mathrm{w}}=0.1,0.5$ and 1 i.e., gust 7, 8 and 9, the ENTR series exhibited more uneven fluctuations as compared to the other ENTR series with higher $\mathrm{f}_{\mathrm{g}} / \mathrm{f}_{\mathrm{w}}$ values. This observation was similar to that inferred from RR, TT and RATIO series.

3.4g Maximum line $\left(L_{\max }\right)$ : This variable deals with the divergence of the trajectory segment. It gives information about the range in which a segment of the trajectory is close to one another at a different time. Length of the diagonal lines is related to the largest positive Lyapunov exponent and characterizes the rate of separation of the infinitesimally closed trajectories in the phase space diagram. $\mathrm{L}_{\max }$ is computed using the expression (11):

$$
L_{\max }=\max \left(\left\{l_{i} ; \quad i=1 \ldots . . N\right\}\right)
$$

$\mathrm{L}_{\max }$ series for the horizontal and vertical force coefficients are shown in figures 20(a) and (b).

It was observed from the comparative plots of the $\mathrm{L}_{\max }$ series that for gusts with $\mathrm{f}_{\mathrm{g}} / \mathrm{f}_{\mathrm{w}}$ of 0.1 and $\mathrm{u}_{\mathrm{g}} / \mathrm{u}_{\mathrm{w}-}$ $=0.1,0.5$ and 1 i.e., gust 7,8 and 9 , the $L_{\max }$ series exhibited more uneven fluctuations as compared to the other $L_{\max }$ series with higher $\mathrm{f}_{\mathrm{g}} / \mathrm{f}_{\mathrm{w}}$ values. This observation was similar to that inferred from RR, TT, RATIO and ENTR series.

3.4h Trend (TREND): Trend is a linear regression coefficient over the recurrence point density of the diagonal lines parallel to the Line of Identity (LoI). It is a function of the time distance between diagonals and LoI. It gives information about the non-stationary nature in the process like a drift. It is computed using the expression (12): 


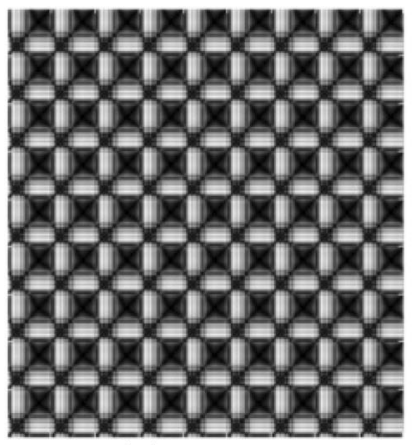

(a) Gust 1

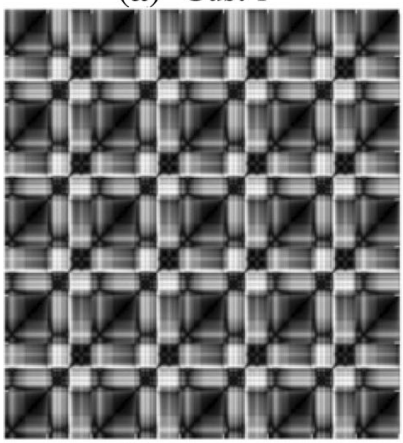

(d) Gust 4

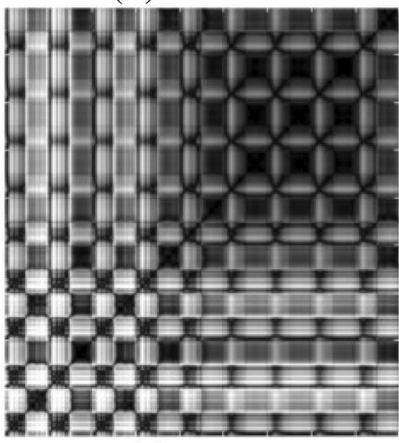

(g) Gust 7

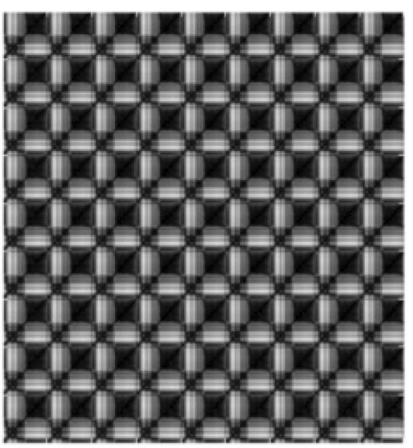

(b) Gust 2

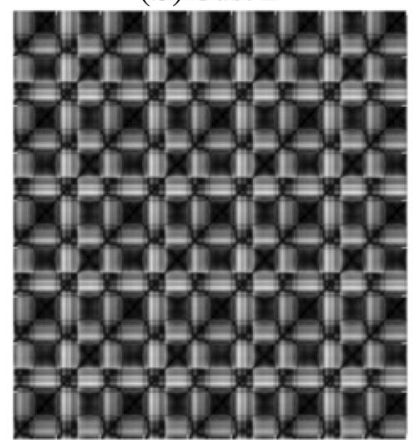

(e) Gust 5

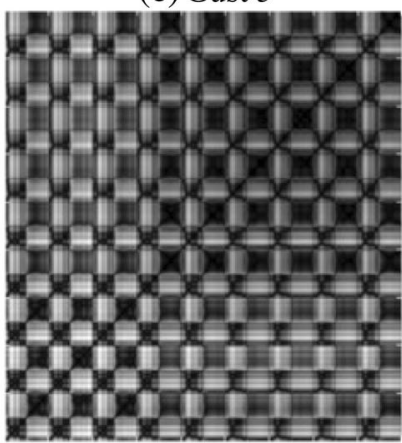

(h) Gust 8

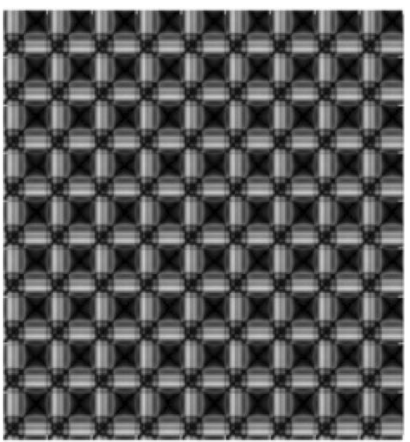

(c) Gust 3

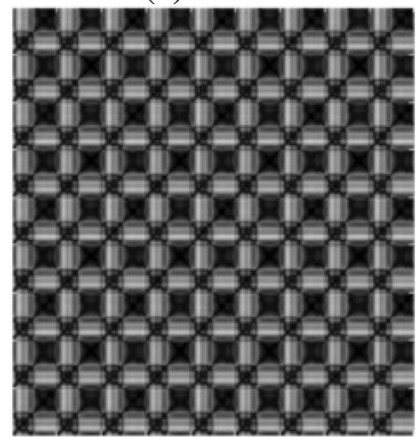

(f) Gust 6

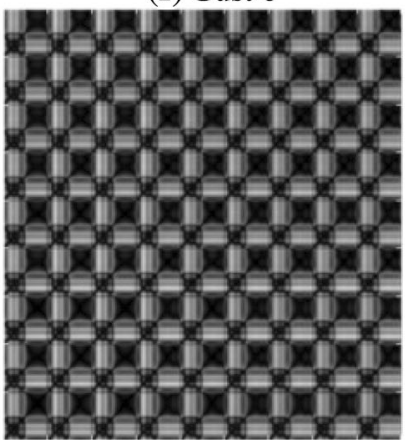

(i) Gust 9

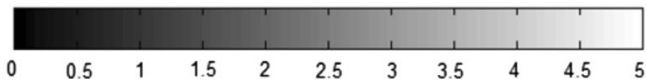

Figure 13. Global recurrence plots for different gusts [top row: $f_{g} / f_{w}=1 ;$ middle row: $f_{g} / f_{w}=0.5$; bottom row: $f_{g} / f_{w}=0.1 ;$ left column: $\mathrm{u}_{\mathrm{g}} / \mathrm{u}_{\mathrm{w}}=1$; middle column: $\mathrm{u}_{\mathrm{g}} / \mathrm{u}_{\mathrm{w}}=0.5$; right column: $\left.\mathrm{u}_{\mathrm{g}} / \mathrm{u}_{\mathrm{w}}=0.1\right]$.

$$
T R E N D=\frac{\sum_{i=1}^{N}(i-N / 2)\left(R R_{i}-R R_{i}\right)}{\sum_{i=1}^{N}(i-N / 2)^{2}}
$$

Here, $\left\langle R R_{i}\right\rangle$ is the average Recurrence rate of the $i^{\text {th }}$ diagonal line. TREND series for the horizontal and vertical force coefficients are shown in figures 21 (a) and (b).

Comparative plots revealed that for gusts with $\mathrm{f}_{\mathrm{g}} / \mathrm{f}_{\mathrm{w}}$ of 0.1 and $u_{\mathrm{g}} / \mathrm{u}_{\mathrm{w}}=0.1,0.5$ and 1 i.e., gust 7,8 and 9 , the TREND series exhibited relatively higher uneven fluctuations. This observation was similar to that inferred from the RR, TT, RATIO, ENTR and $\mathrm{L}_{\text {MAX }}$ series. Standard deviations of all the recurrence variables series based on the horizontal and vertical force coefficients are computed and tabulated in tables 5 and 6.
It was observed from tables 5 and 6 that standard deviation values of all the recurrence variable series based on horizontal and vertical force coefficients for gusts with $\mathrm{f}_{\mathrm{g}} / \mathrm{f}_{\mathrm{w}}$ of 0.1 and $\mathrm{u}_{\mathrm{g}} / \mathrm{u}_{\mathrm{w}}=0.1,0.5$ and 1 viz. gust 7,8 and 9 were relatively higher as compared to that based on gusts with higher $\mathrm{f}_{\mathrm{g}} / \mathrm{f}_{\mathrm{w}}$. However, standard deviation values of DET and LAM series with $\mathrm{f}_{\mathrm{g}} / \mathrm{f}_{\mathrm{w}}$ of 0.1 and $\mathrm{u}_{\mathrm{g}} / \mathrm{u}_{\mathrm{w}}$ of 1 i.e., gust 7 exhibited noticeably higher values as compared to the gusts with higher $\mathrm{f}_{\mathrm{g}} / \mathrm{f}_{\mathrm{w}}$ and lower $\mathrm{u}_{\mathrm{g}} / \mathrm{u}_{\mathrm{w}}$. This was more prominently observed for standard deviation values computed based on the vertical force coefficient. As mentioned earlier, high values of standard deviation of a series implied higher uneven fluctuation of a series. These inferences endorse the conclusions drawn from the plots of the recurrence variable series in a more quantitative manner. 


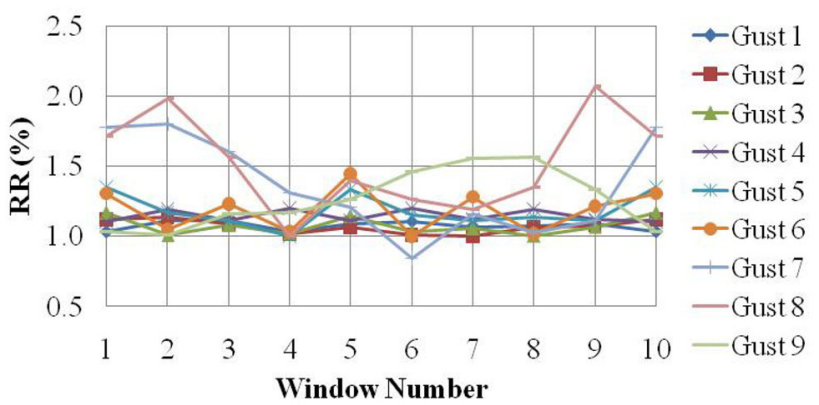

(a) Recurrence rate series of horizontal force coefficient with different gusts.

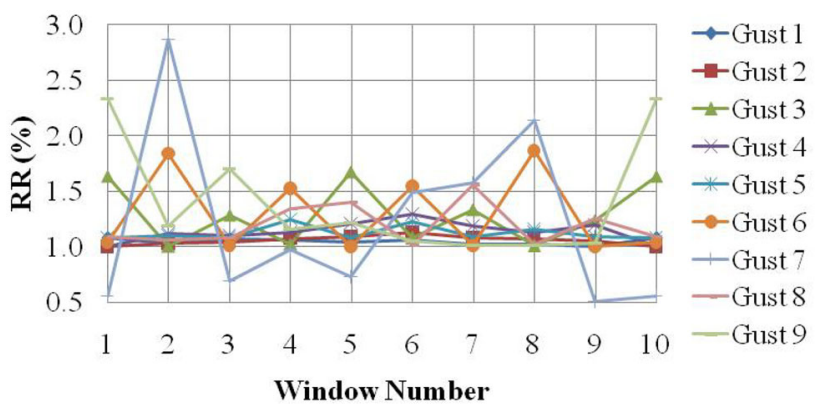

(b) Recurrence rate series of vertical force coefficient with different gusts.

Figure 14. (a) Recurrence rate series of horizontal force coefficient with different gusts. (b) Recurrence rate series of vertical force coefficient with different gusts.

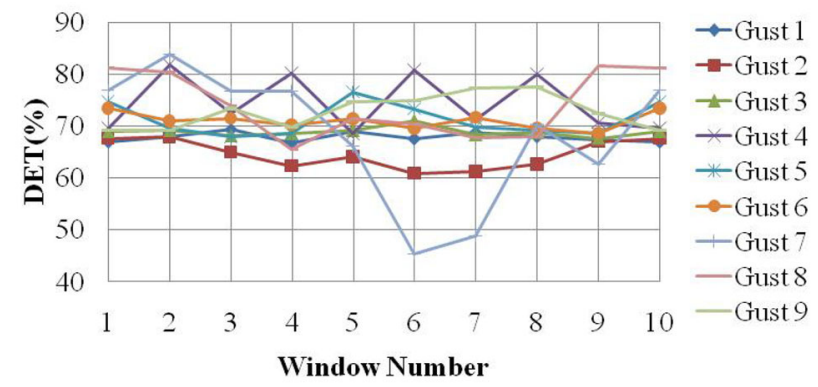

(a) Determinism series of horizontal force coefficient with gusts.

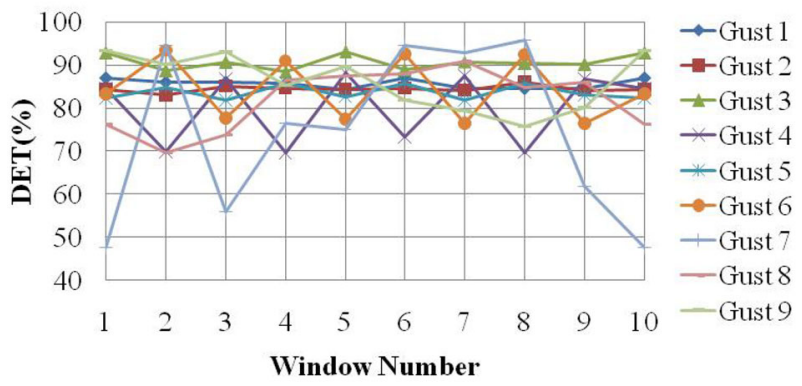

(b) Determinism series of vertical force coefficient with gusts.

Figure 15. (a) Determinism series of horizontal force coefficient with gusts. (b) Determinism series of vertical force coefficient with gusts.

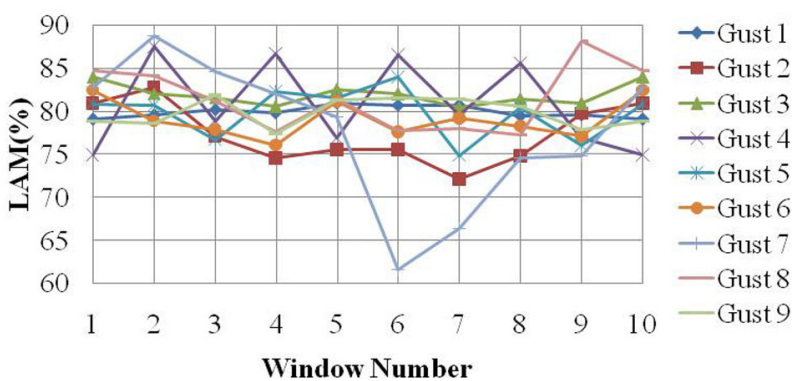

(a) Laminarity series of horizontal force coefficient with different gusts.

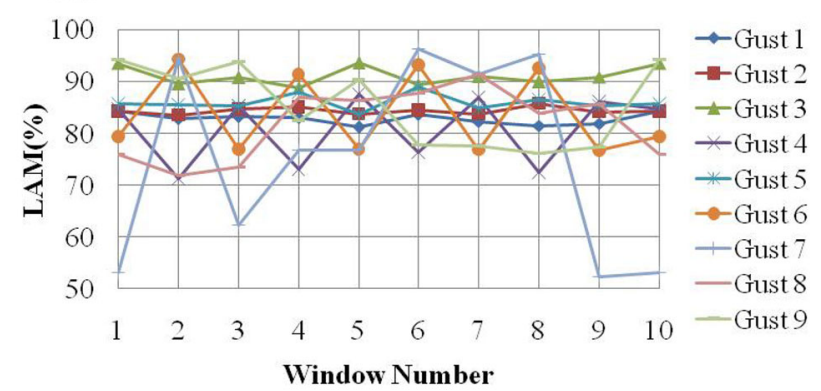

(b) Laminarity series of vertical force coefficient with different gusts.

Figure 16. (a) Laminarity series of horizontal force coefficient with different gusts. (b) Laminarity series of vertical force coefficient with different gusts.

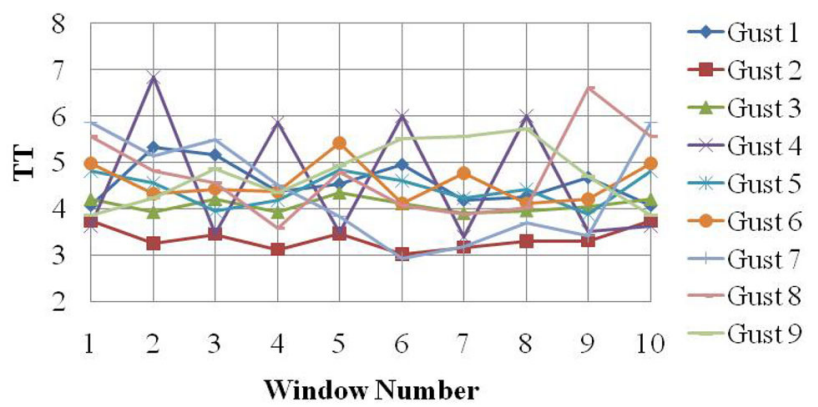

(a) Trapping time series of horizontal force coefficient with different gusts.

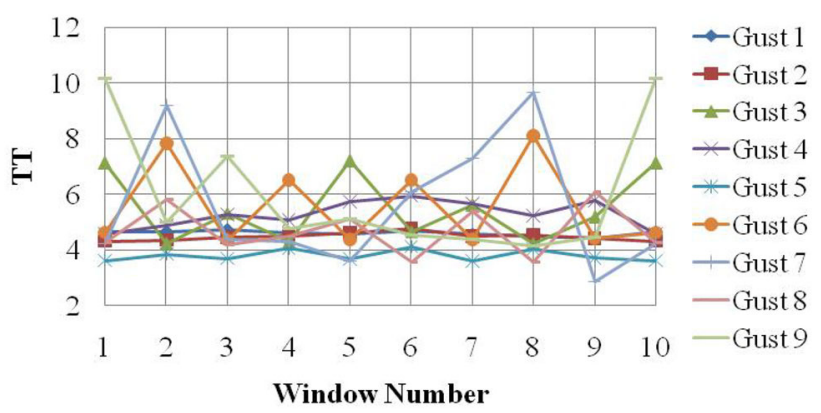

(b) Trapping time series of vertical force coefficient with different gusts.

Figure 17. (a) Trapping time series of horizontal force coefficient with different gusts. (b) Trapping time series of vertical force coefficient with different gusts. 


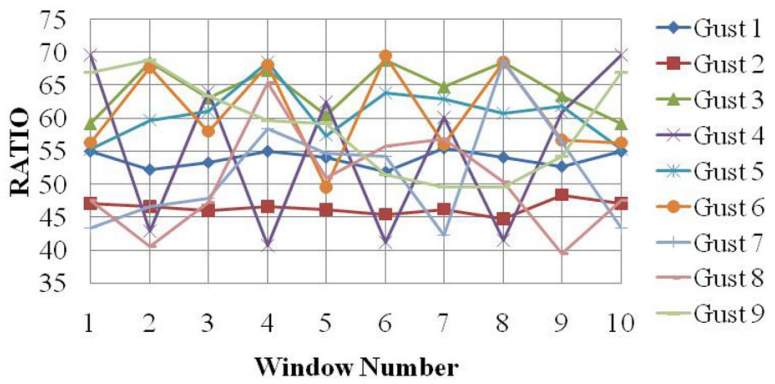

(a) Ratio series of horizontal force coefficient with different gusts.

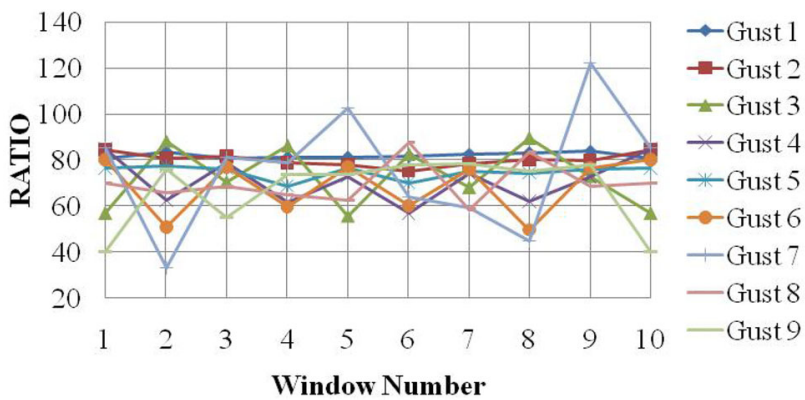

(b) Ratio series of vertical force coefficient with different gusts.

Figure 18. (a) Ratio series of horizontal force coefficient with different gusts. (b) Ratio series of vertical force coefficient with different gusts.

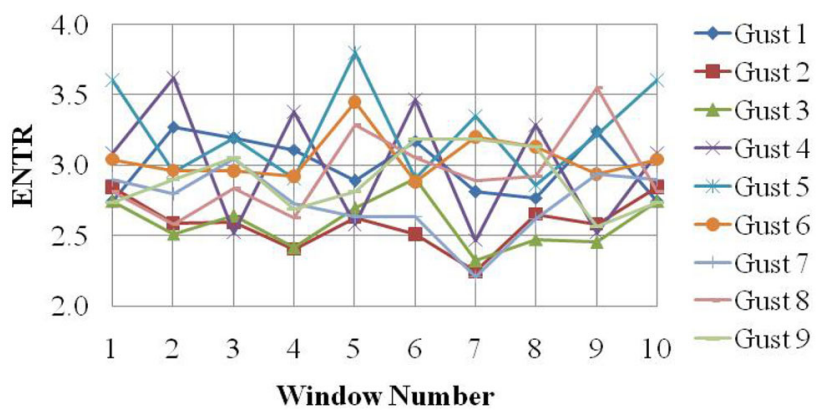

(a) Entropy series of horizontal force coefficient with different gusts.

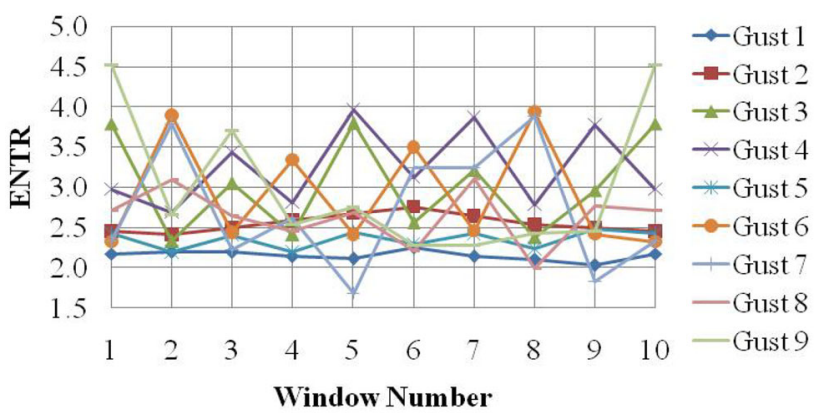

(b) Entropy series of vertical force coefficient with different gusts.

Figure 19. (a) Entropy series of horizontal force coefficient with different gusts. (b) Entropy series of vertical force coefficient with different gusts.

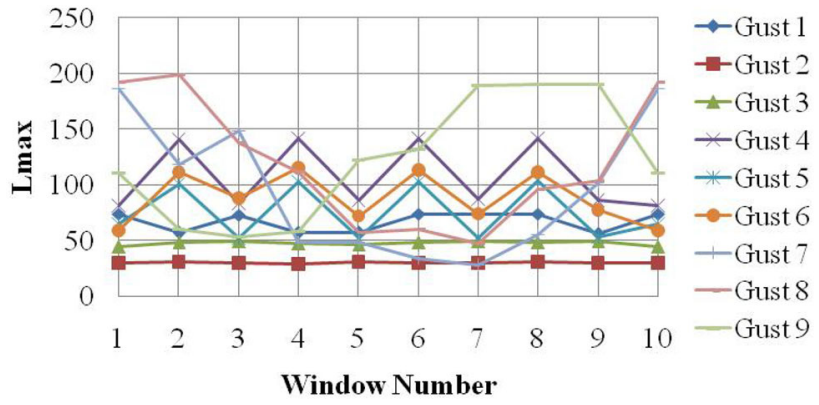

(a) $\mathrm{L}_{\max }$ series of horizontal force coefficient with different gusts.

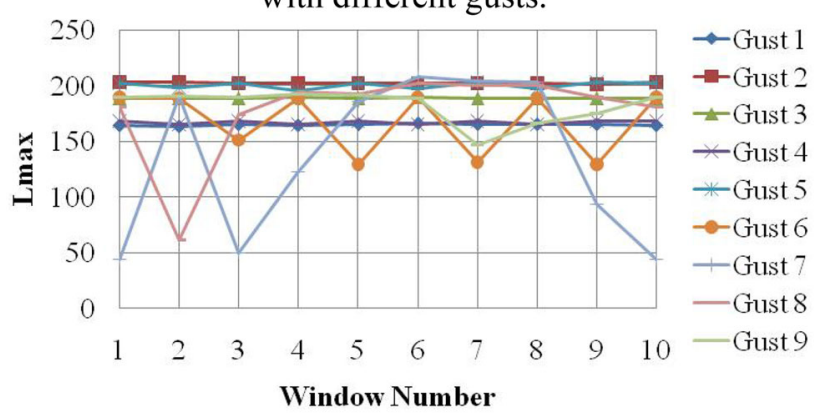

(b) $\mathrm{L}_{\max }$ series of vertical force coefficient with different gusts.

Figure 20. (a) $\mathrm{L}_{\max }$ series of horizontal force coefficient with different gusts. (b) $\mathrm{L}_{\max }$ series of vertical force coefficient with different gusts.

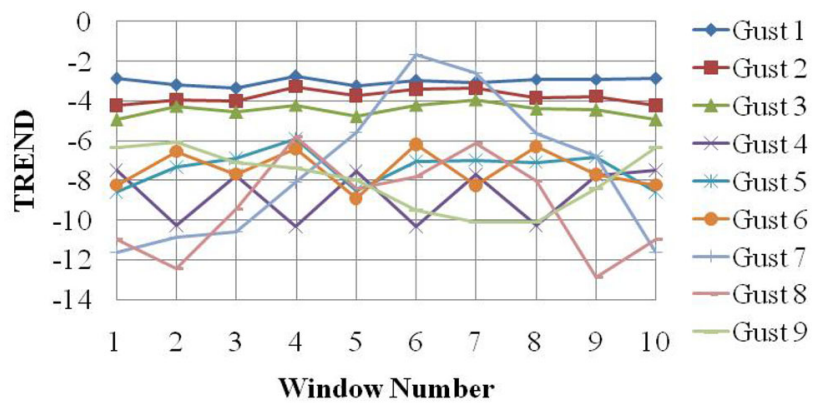

(a) Trend series of horizontal force coefficient with different gusts.

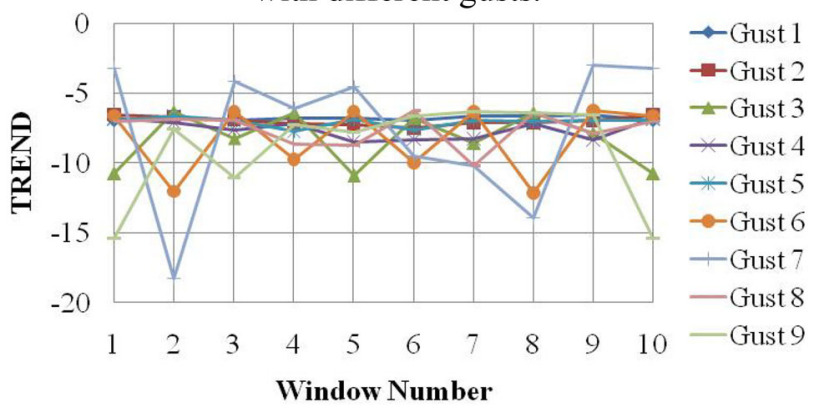

(b) Trend series of vertical force coefficient with different gusts.

Figure 21. (a) Trend series of horizontal force coefficient with different gusts. (b) Trend series of vertical force coefficient with different gusts. 
Table 5. Standard deviation based on horizontal force coefficient.

\begin{tabular}{|c|c|c|c|c|c|c|c|c|}
\hline Gust & $\mathrm{RR}$ & DET & LAM & $\mathrm{TT}$ & RATIO & ENTR & $\mathrm{L}_{\max }$ & TREND \\
\hline Gust 1 & 0.064 & 2.777 & 3.474 & 0.453 & 3.870 & 0.223 & 8.832 & 0.345 \\
\hline Gust 2 & 0.048 & 0.969 & 1.232 & 0.245 & 1.289 & 0.184 & 1.932 & 0.340 \\
\hline Gust 3 & 0.033 & 0.887 & 0.685 & 0.153 & 0.994 & 0.182 & 0.632 & 0.193 \\
\hline Gust 4 & 0.153 & 5.437 & 5.158 & 1.126 & 8.438 & 0.340 & 29.890 & 1.384 \\
\hline Gust 5 & 0.121 & 1.582 & 2.956 & 0.442 & 7.081 & 0.295 & 24.395 & 1.000 \\
\hline Gust 6 & 0.044 & 3.180 & 2.203 & 0.356 & 4.051 & 0.170 & 22.772 & 0.907 \\
\hline Gust 7 & 0.352 & 12.788 & 8.471 & 1.396 & 12.239 & 0.443 & 61.623 & 3.657 \\
\hline Gust 8 & 0.345 & 6.416 & 3.812 & 0.937 & 7.746 & 0.295 & 58.445 & 2.472 \\
\hline Gust 9 & 0.214 & 3.290 & 1.683 & 0.687 & 7.490 & 0.226 & 54.592 & 1.535 \\
\hline
\end{tabular}

Table 6. Standard deviation based on vertical force coefficient.

\begin{tabular}{|c|c|c|c|c|c|c|c|c|}
\hline Gust & $\mathrm{RR}$ & DET & LAM & $\mathrm{TT}$ & RATIO & ENTR & $\mathrm{L}_{\max }$ & TREND \\
\hline Gust 1 & 0.272 & 1.751 & 0.687 & 1.236 & 13.451 & 0.606 & 0.843 & 1.900 \\
\hline Gust 2 & 0.039 & 1.104 & 1.849 & 0.143 & 2.839 & 0.112 & 0.632 & 0.316 \\
\hline Gust 3 & 0.026 & 0.723 & 1.075 & 0.093 & 1.304 & 0.059 & 0.422 & 0.157 \\
\hline Gust 4 & 0.366 & 8.283 & 7.965 & 1.517 & 12.261 & 0.681 & 28.314 & 2.486 \\
\hline Gust 5 & 0.091 & 7.299 & 6.719 & 0.498 & 9.992 & 0.480 & 2.998 & 0.667 \\
\hline Gust 6 & 0.065 & 1.727 & 1.492 & 0.206 & 2.893 & 0.110 & 1.552 & 0.349 \\
\hline Gust 7 & 0.797 & 19.800 & 18.691 & 2.380 & 26.484 & 0.893 & 71.536 & 5.249 \\
\hline Gust 8 & 0.530 & 7.254 & 6.921 & 2.362 & 15.639 & 0.779 & 41.948 & 3.631 \\
\hline Gust 9 & 0.188 & 6.564 & 7.866 & 0.887 & 8.970 & 0.348 & 14.744 & 1.270 \\
\hline
\end{tabular}

It was thus inferred from these comparisons that DET and LAM gave a more precise indication of the onset of unstable behaviour of the system i.e., precise gust frequency and gust amplitude which resulted in increase of uneven fluctuations of the force coefficient based windowed recurrence variable series. As compared to them, the other six recurrence variables indicated a specific gust frequency but a range of gust amplitude for which the uneven fluctuations of the windowed series were observed. Also, as compared to the standard deviation values of the horizontal force coefficient based windowed recurrence variable series, the values were prominently higher for the vertical force coefficient based windowed recurrence variable series. Hence computing vertical force coefficient based WRQA of DET or LAM series and their standard deviations would be adequate in capturing the uneven fluctuations and uncertainty occurring in the recurrence variable series. More uneven fluctuation of the recurrence variable series or higher values of standard deviation indicated an onset of instabilities in the force patterns of the flapping wing system due to the gusty conditions.

\section{Conclusions}

Effects of a frontal gust on force patterns of the insectsized flapping wing in an inclined-stroke plane in 2D reference frame for $\mathrm{Re}=150$ were assessed using Global Recurrence Plots (GRP) and Windowed Recurrence
Quantification Analysis (WRQA). These recurrence paradigms provided a computationally cost-effective way to assess the possibility of an onset of unstable behaviour in the flapping wing system under a given gusty condition. Inferences were qualitatively made based on textures of GRPs and quantitatively by the plots of force coefficient based recurrence variables series and computing the standard deviations of these series. The studies indicated that gusts with gust frequency of an order of magnitude lower than the flapping frequency and gust amplitude of the order of wing's root mean square averaged flapping velocity caused an unstable force pattern. The onset of instability was effectively captured qualitatively by GRPs and quantitatively by WRQA of vertical force coefficient and plots of the DET or LAM series and their respective standard deviations.

$\begin{array}{ll}\text { Nomenclature } \\ c & \text { wing chord length, cm } \\ f_{w} & \text { wing flapping frequency, Hz } \\ f^{*} & \frac{1}{2 \pi\left(\frac{\mathrm{A}_{0}}{\mathrm{C}}\right)} \\ & \text { diagonal line } \\ 1 & \text { minimum threshold diagonal line } \\ l_{\text {min }} & \text { dimensional phase space trajectory } \\ \mathrm{m} & \text { time, sec } \\ t & \text { non-dimensionalized time }\end{array}$




\begin{tabular}{|c|c|}
\hline$t_{w}, T$ & period of flapping in second \\
\hline$u_{g}$ & gust amplitude, $\mathrm{m} / \mathrm{s}$ \\
\hline$u_{w}$ & $\begin{array}{l}\text { root mean square average flapping velocity at } \\
\text { the tip of the wing, } \mathrm{m} / \mathrm{s}\end{array}$ \\
\hline$u_{\text {Resultant }}$ & resultant velocity, $\mathrm{m} / \mathrm{s}$ \\
\hline$u_{G}$ & gust velocity, $\mathrm{m} / \mathrm{s}$ \\
\hline$u_{\infty}$ & mean free stream velocity, $\mathrm{m} / \mathrm{s}$ \\
\hline $\overrightarrow{\mathrm{u}}$ & flow velocity, $\mathrm{m} / \mathrm{s}$ \\
\hline $\overrightarrow{\mathrm{ug}_{\mathrm{g}}}$ & velocity of the moving mesh, $\mathrm{m} / \mathrm{s}$ \\
\hline $\mathrm{v}$ & length of vertical structures in recurrence plot \\
\hline $\mathrm{v}_{\min }$ & minimum threshold vertical line \\
\hline Ao & stroke length of the wing, $\mathrm{cm}$ \\
\hline $\mathrm{B}$ & pitching angle amplitude, deg \\
\hline $\mathrm{C}_{\mathrm{H}}$ & coefficient of horizontal force \\
\hline $\mathrm{C}_{\mathrm{V}}$ & coefficient of vertical force \\
\hline $\mathrm{F}_{\text {Drag }}$ & drag force, Newton \\
\hline $\mathrm{F}_{\text {Horizontal }}$ & horizontal force, Newton \\
\hline $\mathrm{F}_{\text {Lift }}$ & lift force, Newton \\
\hline $\mathrm{F}_{\text {Resultant }}$ & resultant force, Newton \\
\hline $\mathrm{F}_{\text {Vertical }}$ & vertical force, Newton \\
\hline $\mathrm{L}_{\max }$ & $\begin{array}{l}\text { maximum diagonal structure of the recurrence } \\
\text { plot }\end{array}$ \\
\hline $\mathrm{N}$ & length of data series \\
\hline$P^{\varepsilon}(l)$ & frequency distribution of the diagonal lengths 1 \\
\hline$P^{\varepsilon}(v)$ & frequency distribution of vertical length, $v$ \\
\hline$R_{i, j}^{m, \varepsilon}$ & $\begin{array}{l}\text { recurrence matrix of an } \mathrm{m} \text {-dimensional phase } \\
\text { space trajectory and a neighbourhoods radius } \varepsilon\end{array}$ \\
\hline $\mathrm{S}_{\phi}$ & source term \\
\hline $\mathbf{V}$ & arbitrary control volume \\
\hline
\end{tabular}

\section{Greek symbols}

$\alpha(\mathrm{t}) \quad$ instantaneous pitching angle, deg

$\alpha_{0} \quad$ mean pitching angle, deg

$\beta \quad$ stroke plane angle, deg

$\Upsilon \quad$ elliptical flow domain around the wing

$\varepsilon \quad$ neighbourhood radius

$\varnothing \quad$ a scalar quantity

$\rho \quad$ fluid density, $\mathrm{kg} / \mathrm{m}^{3}$

$\Gamma \quad$ diffusion coefficient

\section{References}

[1] Ellington C P 1984 The Aerodynamics of hovering insect flight: III. Kinematics. Philos. Trans. R. Soc. London Ser. B 305: 41-78

[2] Berman G and Wang Z J 2007 Energy-minimizing kinematics in hovering insect flight. J. Fluid Mech. 582: 153-168

[3] Meng X and Sun M 2016 Wing kinematics, aerodynamic forces and vortex-wake structures in fruit-flies in forward flight. J. Bionic Eng. 13: 478-490

[4] Ansari S A, Knowles K and Zbikowski R 2008 Insectlike flapping wings in the hover: Part II Effect of wing geometry. J. Aircraft 45: 1976-1990

[5] Singh B and Chopra I 2008 Insect-based hover-capable flapping wings for micro air vehicles: experiments and analysis. AIAA J. 46: 2115-2135
[6] Meng X, Liu Y and Sun M 2017 Aerodynamics of ascending flight in fruit flies. J. Bionic Eng. 14: 75-87

[7] Berg A M and Biewerner A A 2008 Kinematics and power requirements of ascending and descending flight in the pigeon. J. Exp. Biol. 211: 1120-1130

[8] Nagai H, Isogai K, Fujimoto T and Hayase T 2009 Experimental and numerical study of forward flight aerodynamics of insect flapping wing. AIAA J. 47: 730-742

[9] Xiang J, Du J, Li D and Liu K 2016 Aerodynamic performance of the locust wing in gliding mode at low Reynolds number. J. Bionic Eng. 13: 249-260

[10] Fry S N, Sayaman R and Dickenson M H 2003 The aerodynamics of free-flight maneuvers in drosophila. Science 300: 495-498

[11] Broering T M and Lian Y 2012 The effect of phase angle and wing spacing on tandem flapping wings. Acta Mech. Sin. 28: $1557-1571$

[12] Combes S A and Daniel T L 2003 Flexural stiffness in insect wings I. Scaling and the influence of wing venation. J. Exp. Biol. 206: 2979-2987

[13] Combes S A and Daniel T L 2003 Flexural stiffness in insect wings II. Spatial distribution and dynamic wing bending. $J$. Exp. Biol. 206: 2989-2997

[14] Heathcote S and Gursul I 2007 Flexible flapping airfoil propulsion at low Reynolds number. AIAA J. 45: 1066-1079

[15] Young J, Walker S M, Bomphery R J, Taylor G K and Thomas A L R 2009 Details of insect wing design and deformation enhance aerodynamic function and flight efficiency. Science 325: 1549-1552

[16] Geng B, Xue Q, Zheng X, Liu G, Ren Y and Dong H 2017 The effect of wing flexibility on sound generation of flapping wings. Bioinspir. Biomim. 13. https://doi.org/10.1088/17483190/aa8447

[17] Gao T and Lu X 2008 Insect normal hovering flight in ground effect. Phys. Fluids 20: 087101-1-11

[18] Srinidhi N G and Vengadesan S 2017 Ground effect on tandem flapping wing hovering. Comput. Fluids 152: $40-56$

[19] Manoukis N C, Butail S, Diallo M, Ribeiro J M C and Paley D A 2014 Stereoscopic video analysis of Anopheles gambiae behavior in the field: Challenges and opportunity. Acta Trop. 132: S80-S85

[20] Sane S P 2003 The aerodynamics of insect flight. J. Exp. Biol. 206: 4191-4208

[21] Platzer M F, Jones K D, Young J and Lai J C S 2008 Flapping-wing aerodynamics: Progress and Challenges. AIAA J. 46: 2136-2155

[22] Shyy W, Aono H, Chimakurthi S K, Trizila P, Kang C K, Cesnik C E S and Liu H 2010 Recent progress in flapping wing aerodynamics and aeroelasticity. Prog. Aerosp. Sci. 46: 284-327

[23] Ward T A, Rezadad M, Fearday C J and Viyapuri R. A 2015 Review of Biomimetic air vehicle research: 1984-2014. Int. J. Micro Air Veh. 7: 375-394

[24] Watkins S, Milbank J, Loxton B J and Melbourne W H 2006 Atmospheric Winds and Their Implications for Micro air Vehicles. AIAA J. 44: 2591-2600

[25] Lian Y and Shyy W 2007 Aerodynamics of Low Reynolds Number Plunging Airfoil under Gusty Environment. In: 45th AIAA Aerospace Sciences Meeting and Exhibit. AIAA Paper 2007-70. pp 1-20 
[26] Wan T and Huang C 2008 Numerical Simulation of Flapping Wing Aerodynamic Performance under Gust Wind Conditions. In: 26th International Congress of the Aeronautical Sciences. pp. 1-11

[27] Lian Y 2009 Numerical study of a flapping airfoil in gusty environments. In: 27th AIAA Applied Aerodynamics Conference. AIAA-2009-3952. pp. 1-13

[28] Viswanath K and Tafti D K 2010 Effect of frontal gusts on forward flapping flight. AIAA J. 48: 2049-2062

[29] Prater R and Lian Y 2012 Aerodynamic response of stationary and flapping wings in oscillatory low Reynolds number flows. In: 50th AIAA Aerospace Science Meeting including the New Horizons Forum and Aerospace Exposition. AIAA-2012-0418. pp. 1 - 17

[30] Sarkar S, Chajjed S and Krishnan A 2013 Study of asymmetric hovering in flapping flight. Eur. J. Mech. B Fluids 37: 72-89

[31] Zhu J, Jiang L, Zhao H, Tao B and Lei B 2015 Numerical study of a variable camber plunge airfoil under wind gust condition. J. Mech. Sci. Technol. 29: 4681-4690

[32] Jones M and Yamaleev N K 2016 Effect of lateral, downward and frontal gusts on flapping wing performance. Comput. Fluids 140: 175-190

[33] Srinidhi N G and Vengadesan S 2017 Lagrangian Coherent Structures in Tandem Flapping Wing Hovering. J. Bionic Eng. 14: 307-316

[34] Durmaz O, Karaca H D, Ozen G D, Kasnakoglun and Kurtulus D F 2013 Dynamical modelling of the flow over a flapping wing using proper orthogonal decomposition and system identification techniques. Math. Comput. Model. Dyn. Syst. 19(2): 133-158

[35] Marwan N 2008 A historical review of recurrence plots. Eur. Phys. J. Spec. Top. 164: 3-12

[36] Poincaré H 1890 On the problem of three bodies and equations of dynamics. Acta Math. 13: 1-270

[37] Monk A T and Compton A H 1939 Recurrence phenomena in cosmic-ray intensity. Rev. Mod. Phys. 11(3-4): 173-179

[38] Eckmann J P, Kamphorst S O and Ruelle D 1987 Recurrence plots of dynamical systems. Europhys. Lett. 4: 973-977

[39] Zbilut J P, Giuliani A and Webber C L Jr 1998 Recurrence quantification analysis and principal components in the detection of short complex signals. Phys. Lett. A. 237: 131-135

[40] Iwanski J S and Bradley E 1998 Recurrence plots of experimental data: to embed or not to embed? Chaos 8: 861-871

[41] Choi J M, Bae B H and Kim S Y 1999 Divergence in perpendicular recurrence plot: quantification of dynamical divergence from short chaotic time series. Phys. Lett. A 263: 299-306

[42] Horai S, Yamada T and Aihara K 1996 Determinism analysis with iso-directional recurrence plots. IEEE Trans. Inst. Electric. Eng. Jpn. C 122: 141-147
[43] Manuca R and Savit R 1996 Stationarity and non-stationarity in time series analysis. Physica D 99: 134-161

[44] Casdagli M C 1997 Recurrence plots revisited. Physica D 108: $12-44$

[45] Zbilut J P and Webber C L Jr 1992 Embeddings and delays as derived from quantification of recurrence plots. Phys. Lett. A 171: 199-203

[46] Marwan N, Wessel N, Meyerfeldt U, Schirdewan A and Kurths J 2002 Recurrence plot based measures of complexity and its application to heart rate variability data. Phys. Rev. E 66: 026702

[47] Badrinath S, Bose C and Sarkar S 2017 Identifying the route to chaos in the flow past a flapping airfoil. Eur. J. Mech. B/ Fluids 66: 38-59

[48] Bose C, Reddy V, Gupta S and Sarkar S 2017 Transient and Stable Chaos in Dipteran Flight Inspired Flapping Motion. $J$. Comput. Nonlin. Dyn. 13: 021014

[49] Bos F M, Lentink D, Oudheusden B W V and Bijl H 2008 Influence of wing kinematics on aerodynamic performance in hovering insect flight. J. Fluid Mech. 594: 341-368

[50] Wood R J, Finio B, Karpelson M and Whitney J P 2012 Progress on pico air vehicles. Int. J. Robot. Res. 31: 1292-1302

[51] Brodsky A K 1994 The Evolution of Insect Flight, Oxford: Oxford University Press

[52] Henderson R D 1995 Details of the drag curve near the onset of vortex shedding. Phys. Fluids 7: 2102-2104

[53] Williamson C H K 1995 Book Chapter: Vortex dynamics in the wake of a cylinder, Fluid Vortices. SI edition, Amsterdam, Holland, Kluwer Academic Publishing, pp. 155-234

[54] Ferziger J H and Peric M 2002 Computational Methods for Fluid Dynamics. 3rd Edition, Heidelberg New York: Springer-Verlag Berlin

[55] Issa R I 1985 Solution of the implicitly discretized fluid flow equations by operator-splitting. J. Comput. Phys. 65: 40-65

[56] Wang Z J 2000 Two dimensional mechanism for insect hovering. Phys. Rev. Lett. 85: 2216-2219

[57] Sudhakar Y and Vengadesan S 2010 Flight force production by flapping insect wings in inclined-stroke plane. Comput. Fluids 39: 683-695

[58] Xu S and Wang Z J 2006 An immersed interface method for simulating the interaction of a fluid with moving boundaries. J. Comput. Phys. 216: 454-493

[59] Harland C and Jacob J D 2010 Gust load testing in a low-cost MAV gust and shear tunnel. In: 27th AIAA Aerodynamic Measurement Technology and Ground Testing Conference. AIAA-2010-4539. pp. 1-14

[60] Zbilut J P, Zaldvar C J M and Strozzi F 2002 Recurrence quantification based Liapunov exponents for monitoring divergence in experimental data. Phys. Lett. A 297: 173-181 